\title{
Obstructive Sleep Apnea Syndrome and Cardiovascular Diseases
}

\author{
Cristiano Fava, M.D., Ph.D., ${ }^{1}$ Martina Montagnana, M.D., ${ }^{2}$ \\ Emmanuel J. Favaloro, Ph.D., M.A.I.M.S., ${ }^{3}$ Gian Cesare Guidi, M.D., ${ }^{2}$ \\ and Giuseppe Lippi, M.D. ${ }^{4}$
}

\section{ABSTRACT}

Obstructive sleep apnea syndrome (OSAS) is a chronic disease characterized by recurrent episodes of partial or complete upper airway collapse and obstruction during sleep, associated with intermittent oxygen desaturation, sleep fragmentation, and symptoms of disruptive snoring and daytime sleepiness. Increasing focus is being placed on the relationship between OSAS and all-cause and cardiovascular disease-related mortality, but it still largely unclear whether this association is causative or simply speculative and epidemiological. Basically, reliable clinical evidence supports the hypothesis that OSAS might be associated with essential and resistant hypertension, as well as with an incremental risk of developing stroke, cardiac rhythm perturbations (e.g., atrial fibrillation, bradyarrhythmias, supraventricular and ventricular arrhythmias), coronary artery disease, acute myocardial infarction, and heart failure. Although it is still unclear whether OSAS might represent an independent risk factor for several acute or chronic conditions, or rather might trigger cardiovascular disease in the presence of traditional cardiovascular risk factors (e.g., obesity, diabetes, and dyslipidemia), there is a plausible biological background underlying this association, in that most of the mechanisms implicated in the pathogenesis of OSAS (i.e., hypoxia, hypercapnia, negative intrathoracic pressure, micro-arousal, sympathetic hyperactivity, metabolic and hormonal changes, oxidative stress, phlogosis, endothelial dysfunction, hypercoagulability, and genetic predisposition) might also be involved in the pathogenesis of cardiovascular disorders. In this article we discuss the different aspects of the relationship between OSAS and pathogenically different conditions such as systemic hypertension, coronary artery disease, stroke, metabolic abnormalities, arrhythmias, and heart failure, and we also discuss the kaleidoscope of phenomena implicated in the pathogenesis of this challenging disease.

KEYWORDS: Sleep apnea, cardiovascular disease, hypertension, stroke, acute myocardial infarction

\footnotetext{
${ }^{1}$ Sezione di Medicina interna C, Dipartimento di Scienze Biomediche e Chirurgiche, Università di Verona, Verona, Italy; ${ }^{2}$ Sezione di Chimica Clinica, Dipartimento di Scienze della Vita e della Riproduzione, Università di Verona, Verona, Italy; ${ }^{3}$ Department of Haematology, Institute of Clinical Pathology and Medical Research (ICPMR), Westmead Hospital, Westmead, Australia; ${ }^{4}$ U.O. di Diagnostica Ematochimica, Dipartimento di Patologia e Medicina di Laboratorio, Azienda Ospedaliero-Universitaria di Parma, Italy. Address for correspondence and reprint requests: Cristiano Fava,

M.D., Ph.D., Department of Medicine, Division of Internal Medicine
}

C, Piazza LA Scuro 10, 37134 Verona, Italy (e-mail: cristiano. fava@med.lu.se).

Coagulopathies and Thrombosis: Usual and Unusual Causes and Associations, Part IV; Guest Editors, Giuseppe Lippi, M.D., Emmanuel J. Favaloro, Ph.D., M.A.I.M.S., and Massimo Franchini, M.D.

Semin Thromb Hemost 2011;37:280-297. Copyright (C) 2011 by Thieme Medical Publishers, Inc., 333 Seventh Avenue, New York, NY 10001, USA. Tel: +1(212) 584-4662.

DOI: http://dx.doi.org/10.1055/s-0031-1273092.

ISSN 0094-6176. 
Obstructive sleep apnea syndrome (OSAS) is a chronic disease characterized by recurrent episodes of partial or complete upper airway collapse and obstruction during sleep, associated with intermittent oxygen desaturation, sleep fragmentation, and symptoms of disruptive snoring and daytime sleepiness. It occurs in patients of all ages, from the premature infant to the elderly, with a prevalence related to age and sex. In the general population of adult men and women, the prevalence is $\sim 3$ to $7 \%$ and 2 to $5 \%$, respectively, ${ }^{1,2}$ increasing significantly in the elderly from $5 \%$ to $9 \% .{ }^{3}$ The prevalence of OSAS in children is between $1 \%$ and $3 \%,{ }^{4}$ although some studies have also reported higher values (e.g., from 5 to $6 \%)^{5}$

OSAS is a complex, multifactorial disorder. The most significant risk factor seems to be upper body obesity $^{6}$ estimated with body mass index (BMI) and neck circumference, followed by male gender, age between 40 and 65 years, cigarette smoking, ${ }^{7}$ use of alcohol, ${ }^{8}$ and physical inactivity. ${ }^{9}$ Others less relevant risk factors include hypothyroidism, ${ }^{10}$ acromegaly, ${ }^{11}$ use of benzodiazepines, ${ }^{12}$ upper airway structural abnormalities, and use of exogenous testosterone. ${ }^{13} \mathrm{~A}$ genetic predisposition, independent from familial obesity, has also been reported in several studies on first-degree relatives and siblings. ${ }^{14-18}$ In particular, it has been observed that a person with one first-degree relative with OSAS has a 40 to $60 \%$ higher risk of developing the disease as compared with an individual with no familial predisposition. ${ }^{16}$ After accounting for socioeconomic status, age, and geographic region, Friberg et al reported that boys with at least one sibling with OSAS had an increased risk of having the disease. The standardized incidence ratio, defined as the ratio of observed to expected cases, was 33.2 in boys and 40.5 in girls, respectively. ${ }^{18}$ Regardless of the etiological factors implicated in the pathogenesis, OSAS is associated with all-cause and cardiovascular disease-related mortality ${ }^{19,20}$ with a reported hazard risk between $1.97^{19}$ and $6.24,{ }^{20}$ which seems to depend on demographic differences in the populations investigated.

It is unclear, however, whether this condition is an independent risk factor for cardiovascular disease, ${ }^{21}$ thus representing a trigger for several acute or chronic cardiovascular conditions such as hypertension, heart failure, arrhythmias, renal disease, stroke, myocardial infarction, sudden death, ${ }^{22}$ or whether it determines cardiovascular disease (CVD) only in association with other traditional cardiovascular risk factors, such as obesity, diabetes, and dyslipidemia and thereby is without a cause-and-effect relationship. ${ }^{6,23}$ In this review we discuss the different aspects of the relationship between OSAS and pathogenically different conditions such as systemic hypertension, coronary artery disease, stroke, metabolic abnormalities, arrhythmias, and heart failure. We also discuss the kaleidoscope of phenomena implicated in the pathogenesis of this challenging disease, including perturbations of the autonomic nervous system, ${ }^{24}$ hypoxemia-reoxygenation cycles leading to endothelial dysfunction, ${ }^{25}$ systemic inflammation, ${ }^{26}$ metabolic-endocrine deregulation, ${ }^{27}$ and coagulationfibrinolysis imbalance. ${ }^{28,29}$

\section{PATHOPHYSIOLOGY OF OBSTRUCTIVE SLEEP APNEA SYNDROME}

How sleep-disordered breathing (SDB) might contribute to the elevation of blood pressure (BP) and increased cardiovascular risk has been the subject of several studies, both in the human and the animal model. In healthy individuals, cardiac vagal tone increases with respect to wakefulness and consequently metabolic rate, whereas sympathetic nervous activity, BP, and heart rate all decrease during sleep (in particular, non-REM sleep). ${ }^{30}$ This normal behavior is disrupted in people suffering from SDB, where repeated episodes of intermittent hypoxia and hypercapnia occur during respiratory efforts to overcome the pharyngeal obstacle. Moreover, these episodes are characterized by continuous changes in pulmonary volume, intrathoracic pressure, and microarousals. ${ }^{31}$ After these events, OSAS patients show permanent oscillations in their hemodynamic parameters during the night. The heart rate, BP, and cardiac output vary incessantly due to the repetition of respiratory events and the rapid changes in alertness (micro-arousals) caused by the ventilatory anomalies. In fact, intermittent increases in heart rate and arterial pressure occur in association with decreases in left ventricular stroke volume immediately following apnea termination. ${ }^{32}$

The major contributors to acute hemodynamic modifications occurring in OSAS patients are hypoxemia, hypercapnia, changes in pulmonary volume/intrathoracic pressure, and micro-arousals. Their causative role has been investigated both in OSAS patients and in healthy subjects, and it was concluded that all these factors contribute in the long term to increased autonomous nervous system (ANS) drive, generation of reactive oxygen species (ROS), impaired endothelial function, and metabolic abnormalities, which in turn stably increase both the BP and the cardiovascular risk (Fig. 1).

\section{Short-Term Modifiers of Hemodynamic Parameters: Hypoxia, Hypercapnia, Negative Intrathoracic Pressure, and Micro-Arousal}

Hypoxemia plays probably the leading role in the pathophysiology of OSAS. ${ }^{33}$ Hypoxia is per se a stimulus able to heighten $\mathrm{BP}$ and blunt vascular responsiveness both in OSAS patients and healthy subjects. Patients suffering from OSAS show greater increases in heart rate and mean arterial pressure than control subjects and a 


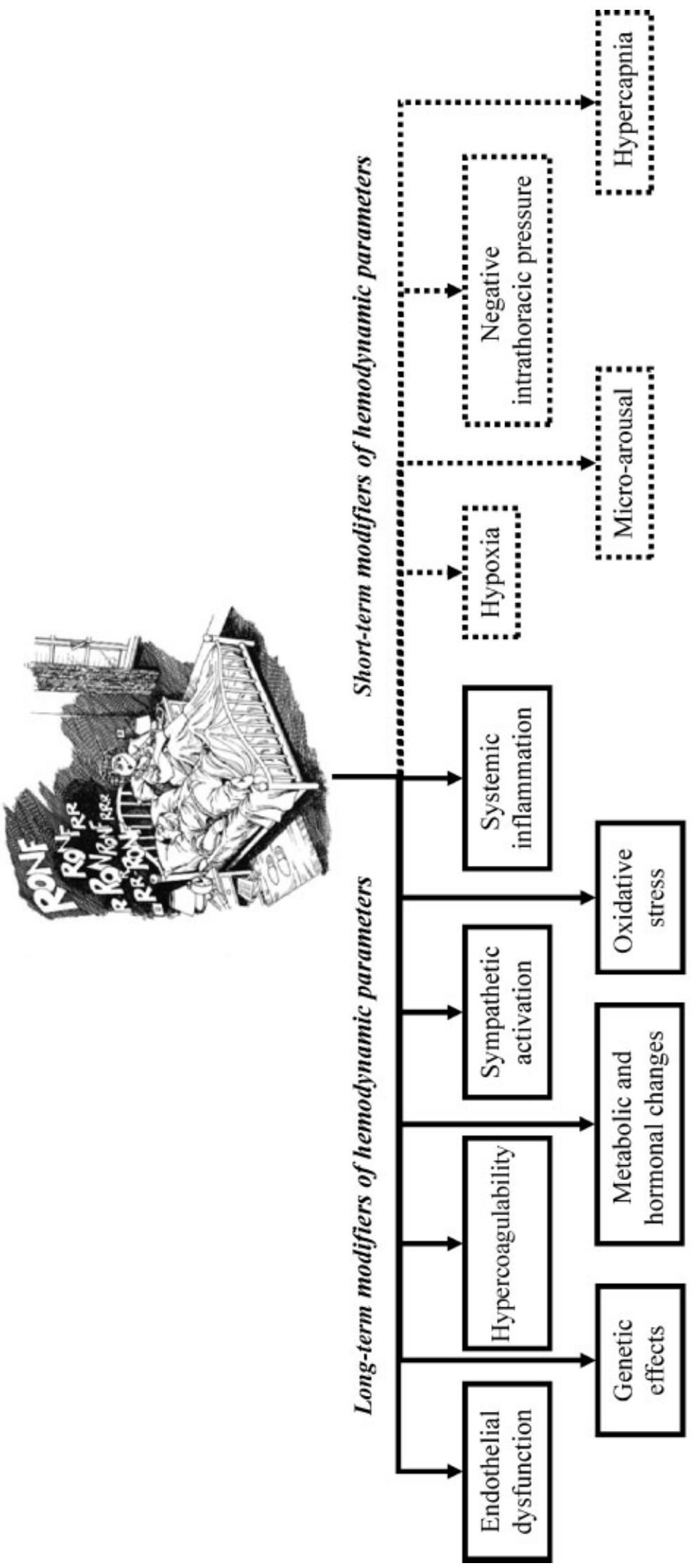


relative increase in muscle sympathetic nerve activity (MSNA), despite higher ventilation and $\mathrm{BP} .{ }^{34}$ Similarly, after 14 nights of nocturnal sustained hypoxia, healthy volunteers showed a significant increase in mean arterial pressure, MSNA, forearm vascular resistance, and forearm blood flow, a response partially corrected by vascular infusion of the $\alpha$-blocker phentolamine. ${ }^{35}$

Although it is a sympathetic stimulation factor, hypercapnia plays a secondary role in the pathophysiology of OSAS, at least in humans. In contrast to rats exposed to intermittent hypoxia where the sympathetic response increases due to both hypercapnia and hypoxia, ${ }^{36}$ some studies in humans demonstrated that the sympathetic response to hypercapnia is not increased in apneic patients as compared with control subjects, ${ }^{34}$ although others authors consider its role still plausible. ${ }^{37}$

By measuring esophageal pressure during apneic episodes, it has been demonstrated that very negative intrathoracic pressures could alter the mechanical properties of the left ventricle (LV). The existence of a sudden restoration of the LV function during normalization of esophageal pressure could lead to the postapnea hypertensive peak. ${ }^{33}$

Micro-arousal is a common pattern in OSAS ${ }^{38,39}$ and is thought to cause periodic fluctuation in BP. Micro-arousal (even as a nonrespiratory event) can also trigger a hypertensive peak during the change to the subject's state of alertness. ${ }^{32}$ The BP peak obtained in normal subjects is proportional to the intensity of the nonrespiratory micro-arousal produced. ${ }^{40}$

\section{Long-Term Modifiers of Hemodynamic Parameters: Sympathetic Activity, Metabolic and Hormonal Changes, Oxidative Stress, Phlogosis, Endothelial Dysfunction, Hypercoagulability, and Genetic Effects}

The ANS plays an essential role in the genesis of the organism's acute and chronic responses to OSAS, and it at least partly explains the physiopathological mechanisms behind the chronic cardiovascular consequences linked to OSAS, particularly hypertension. ${ }^{33}$ In dogs, as well as in rats, repetitive episodic hypoxia mimicking OSAS leads to sustained increase in BP, whereas sleep fragmentation produced only acute but not chronic changes in $\mathrm{BP}^{41-43}$

Since the early 1980s, a predominant role of ANS in the pathophysiology of OSAS has been delineated also in humans: Vagus nerve stimulation explains the initial bradycardia during the apneic phases, ${ }^{44-46}$ whereas in the long term, adaptation to hypoxia and hemodynamic changes occurring at repetitive apneas determines a constantly increase sympathetic activity, which occurs not only during sleep but also while awake, ${ }^{47,48}$ with an effect independent from obesity. ${ }^{49,50}$ The urinary and plasma levels of catecholamines are also increased in these patients. ${ }^{51-54}$

As already described, hypoxia is probably the major trigger of ANS stimulation, although repeated arousals and abnormal respiratory efforts might also play a role. ${ }^{52}$ In a series of experiments aimed to elucidate the role of chemoreceptors and baroreceptors in this setting, Narkiewicz and colleagues found that OSAS is associated with a selective amplificatory effect of autonomic, hemodynamic, and ventilatory responses to peripheral tonic chemoreceptor activation by hypoxia. ${ }^{34,55}$ Moreover, normotensive patients with OSAS have a blunted increase in MSNA for the same difference in mean arterial pressure in response to baroreceptor deactivation (obtained by nitroprusside infusion) but not to baroreceptor activation (tested by phenylephrine infusion). Interestingly, this response is not accompanied by any impairment of baroreflex control of heart rate. ${ }^{56}$ Other groups confirmed the impairment of chemoreceptors and baroreceptors in these patients. ${ }^{57-59}$ Several studies have found that continuous positive airway pressure (CPAP) reduces the hyperactivation of the adrenergic system by ameliorating the oxygenation in OSAS patients. ${ }^{48,60-62}$

Besides the altered secretion of catecholamines, the renin-angiotensin system and other vasoactive hormones have also been measured in OSAS, obtaining controversial results. Independent research groups found higher plasma level of endothelin-1 but not angiotensin II, renin, and aldosterone in patients with OSAS, ${ }^{63,64}$ whereas Møller and colleagues observed increased plasma angiotensin II and aldosterone but not endothelin-1. In the latter study, long-term CPAP reduced BP, and this decrease was correlated with the reductions in plasma renin and angiotensin II levels. ${ }^{65}$ Others studies showed that aldosterone can sustain a resistant form of hypertension in OSAS, independently from renin stimulation. ${ }^{66,67}$ Increased levels of serum angiotensin II and vascular endothelial growth factor and vascular endothelial growth factor mRNA expression were also found in leukocytes of patients with OSAS, ${ }^{68}$ but recent studies suggest caution in interpreting these findings. ${ }^{69}$

Both insulin resistance and the metabolic syndrome amplify the effects of OSAS on sympatheticadrenergic stimulation. ${ }^{70}$ There are also some reports that OSAS might be associated with markers of insulin resistance $^{71-74}$ and could itself trigger type 2 diabetes mellitus (T2DM) ${ }^{75,76}$ Moreover, CPAP may ameliorate some of the metabolic disturbance linked to insulin resistance in OSAS. ${ }^{71,73,76-78}$ To support this association, it was shown that hypoxia also alters glucose metabolism in healthy volunteers. ${ }^{79}$

It has been observed that OSAS patients have a very high prevalence of metabolic syndrome, as defined in the National Cholesterol Education Program Adult Treatment panel III. ${ }^{80}$ 
Several studies have evaluated the association of leptin, a hormone derived by adipocyte, and OSAS. Leptin is almost invariably associated with OSAS, but controversies exist about the independency of this association from body fat as well as on the effect of CPAP on its plasma level. As such, a leading role of leptin in the pathogenesis of OSAS remains unproved as yet. ${ }^{81-93}$

ROS, elicited by chronic intermittent hypoxia, trigger oxidative damages in rats' brain and provoke hypersomnolence and cognitive impairment that closely resembles that of OSAS patients. ${ }^{94-98}$ In humans, despite some controversies, ${ }^{99}$ intermittent hypoxia has been associated with an increase in oxidative stress in OSAS patients, as differently measured in biological samples and in leucocytes cultures, ${ }^{100-106}$ an effect that could be at least partially reversed by CPAP therapy. ${ }^{100-}$ $102,104,106,107$

Inflammatory mediators are increased in OSAS patients, who are characterized by elevated levels of Creactive protein (CRP), ${ }^{108-110}$ adhesions molecules, ${ }^{111}$ inflammatory ${ }^{106,108-110,112-118}$ but also anti-inflammatory cytokines, ${ }^{119}$ matrix metalloproteinase- $9,{ }^{120}$ and vascular endothelial growth factor, ${ }^{121-126}$ independently from obesity. ${ }^{108-110}$ The beneficial effect of CPAP therapy has been documented in most studies. ${ }^{106,112-114,118,127,128}$ Interestingly, the administration of etanercept, a medication that neutralizes tumor necrosis factor (TNF)- $\alpha$, was associated with a significant reduction of objective sleepiness in obese patients with OSAS, and its effect was approximately threefold higher than that of CPAP. ${ }^{129}$

Endothelial dysfunction is an additional hallmark of OSAS patients, ${ }^{117,130-132}$ as demonstrated by altered flow-mediated dilatation ${ }^{133-138}$ and forearm blood flow after acetylcholine or bradykinin infusion, independent from hypertension. ${ }^{135,136,139-141}$ Treatment aimed at improving the oxygenation such as $\mathrm{CPAP},{ }^{141-144}$ modified Herbst mandibular advancement splint, ${ }^{145}$ tonsillectomy in children, ${ }^{137}$ as well as antihypertensive drugs, ${ }^{142,146}$ antioxidants, ${ }^{147}$ and allopurinol, ${ }^{148}$ were proven to ameliorate the endothelial function. This latter finding further underlines the significant contribution of oxidative stress in this setting. ${ }^{148}$

The altered endothelial function is paralleled by an increase in arterial stiffness, ${ }^{136,149-152}$ an effect improved by the use of antihypertensive drugs ${ }^{149}$ and by the presence of subclinical and overt carotid atherosclerosis. ${ }^{136,150,153-156}$ Homocysteine levels are also increased in patients with OSAS, but the pathogenetic role of this sulfur-containing amino acid remains uncertain. ${ }^{157,158}$

A few studies in OSAS patients have documented platelet hyperactivation ${ }^{131,132}$ and some (but not all) have also noted the presence of a hypercoagulable state $^{159-163}$ with increased levels of plasminogen activator inhibitor- $1^{161,164,165}$ that can be lowered by CPAP. ${ }^{161}$
Regarding potential genetic factors contributing to OSAS, there is no convincing evidence to date that variants in putative genes might be associated with the disease. But most of the completed genetic studies were quite small for sample size, and no genomewide association study has been performed for this pathology. ${ }^{166}$ Nevertheless, interesting data are emerging from a mouse model of impaired circadian rhythm. Mice knockouts for genes implicated in circadian rhythm maintenance (i.e., cryptochrome-1 and cryptochrome-2) express an increased amount of the 3 $\beta$-hydroxyl-steroid-dehydrogenase in the adrenal zona glomerulosa, with enhanced production of aldosterone and a tendency to develop salt-sensitive hypertension. ${ }^{167}$ These data are in agreement with the possible primary role of an independent aldosterone secretion in OSAS patients with resistant hypertension, ${ }^{66,67}$ so their role in patients with OSAS or other forms of sleep disturbance deserves further scrutiny.

\section{OBSTRUCTIVE SLEEP APNEA SYNDROME AND HYPERTENSION}

\section{Epidemiological and Experimental Evidence of Obstructive Sleep Apnea Syndrome Causing Hypertension}

Regardless of the definition used for sleep disorders or OSAS, these pathologies have been increasingly and strikingly associated with essential ${ }^{168-170}$ and resistant hypertension for $>20$ years so far. ${ }^{171,172}$

Both the European and American clinical practice guidelines recognize OSAS as a secondary form of hypertension. ${ }^{26,173}$ However, because the effects of OSAS are closely related to those of obesity, the independent association of breathing disorders with hypertension are sometimes confounded by the high prevalence of obesity in OSAS patients, especially at younger ages. ${ }^{174,175}$

A review of epidemiological and experimental data is helpful to unravel this issue. Participants in the Sleep Heart Health Study, a community-based study involving 6132 subjects recruited from ongoing population-based studies (age $>40$ years) were investigated for SDB. After adjusting for anthropometric variables (including BMI, neck circumference, and waist-to-hip ratio), the odds ratio (OR) for hypertension, comparing the highest category of apnea hypopnea index (AHI) ( $\geq 30$ per hour) with the lowest category $(<1.5$ per hour), was $1.37 .{ }^{176}$

In the same cohort followed prospectively, the ORs for incident hypertension increased with increasing baseline AHI. This relationship was attenuated, however, and nonstatistically significant after adjustment for baseline BMI. ${ }^{177}$ Conversely, in 709 participants of the Wisconsin Sleep Cohort Study, SDB at baseline was associated with the presence of 
hypertension independently of known confounding factors including obesity measures. ${ }^{178}$ In another prospective two-step study involving $>16,000$ people in the first phase and $>1700$ in the second, SDB was independently associated with hypertension. The strength of the association was proportional to the severity of the disorders. The ORs increased from 1.6 for simple snoring to 6.8 for moderate or severe SDB (obstructive apnea/hypopnea index $\geq 15.0$ ). ${ }^{179}$ The relation between SDB and hypertension seems to have a specific association pattern with age because it is attenuated in subjects $>60$ years. ${ }^{179,180}$ The lack of significant association between OSAS and hypertension in the elderly may be due to the fact that OSAS significantly affects survival rate or that, alternatively, significant CVD has already occurred by that age, so the contribution of OSAS on disease progression seems less important. SDB has instead adverse consequences from childhood. In a population of children 5 to 12 years of age, systolic BP was elevated in association with the AHI, reaching a mean of $12.9 \mathrm{~mm} \mathrm{Hg}$ for AHI $\geq 5$ after adjusting for BMI, waist circumference, and other confounding factors. ${ }^{181} \mathrm{In}$ total, these studies underline that although obesity is a common finding in people with $\mathrm{SDB}$, OSAS is independently associated with both the incidence and prevalence of hypertension.

\section{Characteristics of Hypertension in Patients with Sleep-Disordered Breathing}

Interesting clues come from ambulatory BP monitoring in patients with OSAS. These patients do not show the usual fall in BP ( $\sim 10$ to $20 \%$, the so called physiological dipping) that occurs during the night in normal subjects. As such, BP dipping is often insufficient or lacking in these patients. ${ }^{182-186}$ In the clinical setting, a documented nondipper profile on the 24-hour ambulatory $\mathrm{BP}$ monitoring should thereby suggest the possibility of OSAS. ${ }^{168,172,187}$ Masked hypertension is another common finding, occurring in $30 \%$ of these patients. ${ }^{187}$ Moreover, in comparison with people without OSAS, these subjects have an increased in BP variability, ${ }^{188}$ which can increase the overall cardiovascular risk.

The increase in peripheral arterial resistance, due to constantly elevated sympathetic activity, explains the predominantly diastolic nature of the hypertension found in OSAS. Therefore, isolated diastolic hypertension and sometimes systolic/diastolic hypertension are profiles more likely related to OSAS as compared with isolated systolic hypertension. ${ }^{180,189}$

\section{Therapeutic Trials}

Several trials have tested nasal CPAP or bilevel positive airway pressure (BPAP) for their effects on BP. Most of these trials have a limited sample size and other important limitations, including the lack of a control group, no randomization of therapy, brief duration, and office measurement of BP. ${ }^{190-207}$ Data are additionally confounded by different inclusion criteria, with different important covariates such as obesity that may play a primary role. Taken into account all these limitations, three meta-analyses have tried to pull together these data and to provide a definitive answer on this issue. ${ }^{208-210} \mathrm{It}$ seems hence plausible that CPAP or BPAP has a small but significant effect especially on diastolic BP (1 to $2 \mathrm{~mm} \mathrm{Hg}$ ), with a possible positive effect on BP profile during the night. ${ }^{193,211,212}$ Patient characteristics that predict a better $\mathrm{BP}$ response include adherence to therapy, severity of OSAS, and uncontrolled or untreated hypertension. ${ }^{33}$

Other procedures aimed at increasing oxygenation such as a facial mask were adopted and compared in OSAS patients for assessing the BP response, but the outcome was controversial. ${ }^{202,213}$ Also, there are no convincing data concerning conventional antihypertensive treatment to suggest a particular agent or class of agents in these patients. Due to the ANS hyperstimulation at which both OSAS and obesity concur in at least half of these patients, it seems that $\beta$-blockers could be preferable as also suggested by a comparative study. Unfortunately, well-powered randomized trials are completely lacking, so that definitive conclusions cannot be drawn. ${ }^{214}$ Chronic baroreceptor stimulation has been recently proposed for refractory or resistant hypertension. It might be of interest to investigate the effect of this procedure on $\mathrm{BP}$ in patients with SDB because ANS stimulation and baroreceptor impairment are strongly implicated in the pathophysiology of OSAS. ${ }^{215}$

\section{OBSTRUCTIVE SLEEP APNEA SYNDROME AND STROKE}

Several prospective studies have reported that OSAS is associated with an incremental risk of developing stroke ${ }^{19,216,217}$ and that 70 to $95 \%$ of patients with acute stroke or transient ischemic attack manifest OSAS. ${ }^{218,219}$ Artz et al reported an OR for stroke of 4.33 (95\% confidence interval [CI], 1.32 to 14.24 ; $p=0.02)$ in patients affected by SDB. ${ }^{216}$ Accordingly, the cross-sectional data from the Sleep Heart Health Study demonstrated greater odds for stroke in the highest AHI quartile than in the lowest quartile (1.58; $95 \%$ CI, 1.02 to 2.46). ${ }^{220}$ Moreover, OSAS represents a poor prognostic marker; patients affected by this condition show a higher mortality, neurological deterioration, and lower functional abilities after stroke. ${ }^{19,221,222}$

Overall, it seems more plausible that OSAS precedes and represents an independent risk factor for cerebrovascular events ${ }^{19,223,224}$ rather than a consequence. ${ }^{225,226}$ Several mechanisms have been implicated to explain the association between cerebrovascular 
disorders and OSAS. Relevant differences in cerebral blood flow and intracranial pressure have been observed between OSAS patients and healthy subjects ${ }^{227,228}$ other than an impaired cerebral autoregulation. ${ }^{229}$ Dikmenoğlu et al observed that plasma viscosity is high both in the morning and in the evening in severe OSAS patients, probably related to low nocturnal mean oxygen saturation, thus predisposing these patients to stroke. ${ }^{230}$ Moreover, loss of cerebrovascular reactivity and increase of arterial stiffness have been demonstrated, especially during consecutive respiratory events periods. ${ }^{231}$ The patients with severe OSAS have a mean intima-media thickness of the carotid arteries, a marker associated with a high risk of stroke, which was also proven to be significantly higher than those of patients with mild OSAS and control subjects. ${ }^{232}$ Finally, the prevalence of patent foramen ovale, an interatrial communication that can potentially give rise to ischemic stroke by means of paradoxical embolization, is significantly higher in subjects with OSAS than in normal controls. ${ }^{233}$

Coagulation disorders have been described in OSAS patients, including a high morning plasma fibrinogen level, ${ }^{234}$ platelet hyperaggregability, ${ }^{235,236}$ and decreased fibrinolysis, ${ }^{237}$ all of which may play an important role in the pathogenesis of stroke.

Some randomized controlled trials have investigated the effect of CPAP on stroke patients affected by OSAS, ${ }^{238,239}$ but results are not encouraging, probably due to the poor patient compliance or the small size of the study populations.

\section{OBSTRUCTIVE SLEEP APNEA SYNDROME AND ENDOCRINE-METABOLIC DISORDERS}

Growing evidence suggests that OSAS may be causally related to various metabolic abnormalities, including insulin resistance, glucose intolerance, T2DM, and the metabolic syndrome, ${ }^{75,240,241}$ independently of adiposity. ${ }^{240,242,243}$ The increasing severity of OSAS in $\mathrm{pa}^{-}$ tients with T2DM is associated with a higher degree of insulin resistance and poorer glucose control, independent of adiposity and other confounders. ${ }^{244}$ Although a trend toward a higher prevalence of abnormal glucose metabolism has been observed in patients affected by OSAS as compared with control subjects, the real prevalence varies widely among the different populations. In an Asian population, Otake et al found that $>25 \%$ of OSAS patients were diagnosed as having T2DM. ${ }^{245}$ In Hispanic and African Americans, the prevalence of T2DM was $30 \%$ in the group with OSAS as compared with $19 \%$ in those without. ${ }^{246}$ In European populations, Meslier et al reported that the frequencies of T2DM and impaired glucose tolerance in the OSAS patients were $30 \%$ and $20 \%$, respectively, ${ }^{247}$ whereas they were shown to be $11 \%$ and $30 \%$ in the study of Levinson et al. ${ }^{248}$ In a Swedish study, the prevalence of T2DM in OSAS patients was $18.9 \%$ in men and $14.8 \%$ in women, ${ }^{249}$ similar to the Wisconsin Sleep Cohort (14.7\%). ${ }^{250}$ In the study of Coughlin et al, the subjects with OSAS had a high incidence of metabolic syndrome (87\%) as compared with controls (35\%). ${ }^{80}$ These discrepancies in prevalence have been explained by significant differences in age, sex, ethnicity, hypertension, or obesity grade of the study population. In a longitudinal study, Botros et al demonstrated an increased risk of diabetes among patients with sleep apnea (hazard ratio per quartile of OSAS severity: 1.43; CI, 1.10 to $1.86 ; p=0.008$ ), independently of other risk factors including age, race, sex, baseline fasting glucose, BMI, and changes in BMI. ${ }^{75}$

Several factors implicated in the pathogenesis of OSA (e.g., intermittent hypoxia with generation of ROS, elevated sympathetic nervous activity with stimulation of the renin-angiotensin-aldosterone system, sleep fragmentation, and low quantities of slow-wave sleep and cumulative sleep loss, ${ }^{48,251-253}$ seem to have adverse effects on glucose tolerance. In particular, it has been demonstrated that repeated episodes of hypoxia followed by reoxygenation (a hallmark of OSAS) produce increased levels of proinflammatory cytokines and mediators (i.e., interleukin [IL]-6, CRP, leptin, TNF- $\alpha$, IL-1 $\beta$ ), induce intercellular adhesion molecule-1, vascular cell adhesion molecule-1, other than the production endothelin-1 following the oxidative stress. ${ }^{254}$ Moreover, it is plausible that the increase in insulin resistance observed in OSAS patients may depend on the impaired regulation of leptin. ${ }^{251}$

West and colleagues failed to observe any improvement of glycemic control or insulin resistance in T2DM patients treated with CPAP. ${ }^{255}$ In contrast, the study performed by Dawson et $\mathrm{al}^{78}$ suggests that sleeping glucose levels decrease and are more stable when patients with T2DM and OSAS are treated with CPAP. Analogously, Babu et $\mathrm{al}^{256}$ reported a reduction in hemoglobin A1c level that was significantly correlated with days of CPAP use. CPAP therapy also determines a significant reduction of nocturnal glucose variability and improves overnight glucose control. ${ }^{257}$

Several hormonal axes are impaired in OSAS. ${ }^{258}$ The imbalance of the pituitary-gonadal axis ${ }^{259}$ determines variable degrees of hypogonadism in men, independently of increasing age or obesity, ${ }^{260}$ and lower serum estradiol and progesterone ${ }^{261}$ in women, suggesting that OSAS may also be associated with impaired ovarian function. No dysfunction of the hypothalamicpituitary-thyroid axis has been reported, whereas the involvement of the hypothalamic-pituitary-adrenal axis has been shown by an exaggerated response of adrenocorticotropic hormone to corticotropin-releasing hormone, ${ }^{262}$ leading to altered cortisol levels, decreased pancreatic $\beta$-cell activity, elevated growth hormone 
levels, and alterations in neuroendocrine control of appetite. $^{48,263}$

\section{OBSTRUCTIVE SLEEP APNEA SYNDROME AND MYOCARDIAL ISCHEMIA}

Several investigations have demonstrated an increased risk of developing coronary artery disease (CAD) in patients with OSAS, ${ }^{264-269}$ suggesting an independent association even after the adjustment for traditional confounders between these two diseases in both middle-aged men and women. ${ }^{266,268,270}$ In the study of Schäfer et al, ${ }^{267} 30.5 \%$ of angiographically proven CAD patients were found to have OSAS, whereas OSAS was only present in $19.7 \%$ of control subjects. Lee et al recently observed a high prevalence of previously undiagnosed OSAS in patients admitted with acute myocardial infarction (AMI). ${ }^{271}$

Patients affected by OSAS are also characterized by worse outcomes of CAD, ${ }^{272,273}$ and they have a higher degree of late lumen loss, which is a marker of restenosis and vessel remodeling after elective percutaneous intervention. ${ }^{274}$ The OSAS may inhibit the recovery of $\mathrm{LV}$ function in patients with AMI. ${ }^{275}$ The coronary atherosclerotic plaque volume shows a correlation with the frequency of obstructive sleep apnea/ hypopnea episodes and sleep fragmentation. ${ }^{276}$

The severity of OSAS seems to be independently associated with the presence and extent of subclinical coronary disease assessed by coronary artery calcification, also in patients without clinical coronary disease. ${ }^{270}$ Moreover, OSAS is associated with a family history of premature mortality from ischemic heart disease. ${ }^{277}$

The previously described long-term modifiers of hemodynamic parameters, such as the increase of sympathetic activity, the promotion of oxidative stress with following endothelial dysfunction, systemic inflammation, and the hypercoagulability state (all these conditions are involved in the pathogenesis of OSAS) lead to a high-risk proatherogenic state that predisposes to acute ischemic events. It has been proposed recently that activation of the endothelin system, mediated by hypoxia inducible factor-1 activity, might be responsible for the enhanced susceptibility to chronic intermittent hypoxia leading to myocardial ischemia. ${ }^{278}$ These hemodynamic and neurohormonal abnormalities appear more frequently during the night, which might explain the larger incidence of cardiac events in this period. $^{279}$

The treatment of OSAS with CPAP in patients affected by coronary disease leads to a significantly decreased risk for the composite end point of cardiovascular death, acute coronary syndrome, hospitalization for heart failure, or need for coronary revascularization, mainly by reducing sympathetic nerve activity. ${ }^{280-282}$ The same treatment in patients with nocturnal angina leads to reduced frequency of ST-segment depression and relief of nocturnal angina. ${ }^{265,283}$

\section{OBSTRUCTIVE SLEEP APNEA SYNDROME AND ARRHYTHMIAS}

Several forms of cardiac rhythm perturbations have been documented in patients with OSAS, including both supraventricular and ventricular arrhythmias, ${ }^{284}$ which have also been associated with the onset of sudden death. ${ }^{285}$ OSAS is indeed associated with electrocardiogram modifications ${ }^{286-292}$ that can predict future cardiovascular events ${ }^{188}$ and predispose to arrhythmia. ${ }^{286,288-}$ 292 The most common forms of arrhythmias observed in OSAS are nonsustained ventricular tachycardia, sinus arrhythmia (also termed cyclic variation of heart rate) characterized by bradycardia during the apneic phase with subsequent tachycardia on resumption of respiration, second-degree atrioventricular conduction block, and premature ventricular contractions. ${ }^{293,294}$

Several studies have focused on the risk of atrial fibrillation (AF) in OSAS patients. In the Sleep Heart Health Study, ${ }^{295}$ individuals with severe sleep apnea had four times the odds of having AF (OR: 4.02; 95\% CI, 1.03 to 15.74 ) and three times the odds of having nonsustained ventricular tachycardia (OR: 3.40; 95\% CI, 1.03 to 11.20 ) as compared with individuals without OSAS, even after adjusting for possible confounding factors.

The leading mechanisms implicated in the development of AF in OSAS patients include (1) an atrial chamber enlargement due to impairment of intrathoracic pressure, (2) tissue stretch and remodeling at the site where the nidus is localized and from which electrical discharges propagate in $\mathrm{AF}^{296}$ (3) the repetitive oxyhemoglobin desaturation and the reoxygenation that may activate atrial catecholamine-sensitive ion channels thereby resulting in focal discharges that initiate $\mathrm{AF},{ }^{297}$ and (4) an instability in autonomic tone. ${ }^{298}$

It has been demonstrated that improving the nocturnal oxygenation can restore these abnormalities. ${ }^{289-291}$ Moreover, Kanagala and colleagues observed that $\mathrm{AF}$ recurred 1 year after electrical cardioversion in only $42 \%$ of OSAS patients treated with CPAP, compared with $82 \%$ of untreated OSAS patients. ${ }^{299}$ A recently published study performed in a large population of Japanese OSAS patients demonstrated the efficacy of CPAP in preventing OSAS-associated arrhythmias. ${ }^{300}$

These studies have reported an increased association between OSAS and bradyarrhythmias ${ }^{301,302}$ due mainly to parasympathetic hyperactivity that occurs during the apneic phase. In contrast, the Sleep Heart Health Study failed to demonstrate a significant association between bradycardia and OSAS. ${ }^{295}$ Despite these contradictory results, CPAP therapy has been shown to abolish most bradyarrhythmias in OSAS patients. ${ }^{303}$ 


\section{OBSTRUCTIVE SLEEP APNEA SYNDROME AND HEART FAILURE}

Heart failure (HF) is frequently observed in OSAS patients, with a prevalence between $11 \%$ and $37 \% .{ }^{304,305}$ The prevalence is higher in men than in women. ${ }^{305}$ Data obtained in the Sleep Heart Health Study from 6424 men and women have shown a 2.38 times increased likelihood of having $\mathrm{HF}$ in association with OSAS, independent of other risk factors. ${ }^{220}$ The presence of OSAS 21 days after an AMI is also associated with impaired recovery of left ventricular systolic function. ${ }^{275}$ Untreated OSAS is also associated with an increased risk of death in patients with $\mathrm{HF}^{306}$

OSAS is not only a consequence of HF but indeed represents a risk factor for this condition, ${ }^{220}$ independent of hypertension. ${ }^{307} \mathrm{~A}$ causative relationship between OSAS and LV remodeling has been demonstrated, most likely attributable to oxidative stress following hypoxemia. ${ }^{308}$ Other mechanical factors such as the increased cardiac muscle work index due to the increased negative intrathoracic pressure during obstructed breaths ${ }^{309}$ and the changes in venous return due to the negative intrathoracic pressure generated from the inspiratory effort might lead to LV remodeling. ${ }^{310}$ This clinical picture is further worsened by the onset of arrhythmias.

Several grades of cardiac alterations have been reported in OSAS patients, from silent or subclinical echocardiographic left ventricular abnormalities to symptomatic systolic dysfunction. Treatment of OSAS with CPAP seems to improve LV ejection fraction in patients with congestive HF. An Australian study has shown an improvement in LV ejection fraction from $38 \%$ to $43 \%,{ }^{206}$ and the study of Kaneko et al has shown improvements in LV ejection fraction from $25 \%$ to $34 \%$ following treatment with CPAP for 1 month. ${ }^{205}$

\section{CONCLUSIONS}

Taken together, reliable clinical evidences support the hypothesis that OSAS might be associated with essential and resistant hypertension, as well as with an incremental risk of developing stroke, cardiac rhythm perturbations (e.g., AF, bradyarrhythmias, supraventricular and ventricular arrhythmias), CAD, AMI, and HF. There is a strong biological background underlying these associations, in that most of the mechanisms implicated in the pathogenesis of OSAS (i.e., hypoxia, hypercapnia, negative intrathoracic pressure, micro-arousal, sympathetic hyperactivity, metabolic and hormonal changes, oxidative stress, phlogosis, endothelial dysfunction, hypercoagulability, and genetic predisposition) might also be involved in the pathogenesis of these cardiovascular diseases.

\section{REFERENCES}

1. Punjabi NM. The epidemiology of adult obstructive sleep apnea. Proc Am Thorac Soc 2008;5(2):136-143

2. Young T, Palta M, Dempsey J, Skatrud J, Weber S, Badr S. The occurrence of sleep-disordered breathing among middleaged adults. N Engl J Med 1993;328(17):1230-1235

3. Ancoli-Israel S, Kripke DF, Klauber MR, Mason WJ, Fell $\mathrm{R}$, Kaplan O. Sleep-disordered breathing in communitydwelling elderly. Sleep 1991;14(6):486-495

4. Newacheck PW, Taylor WR. Childhood chronic illness: prevalence, severity, and impact. Am J Public Health 1992; 82(3):364-371

5. Guilleminault C, Lee JH, Chan A. Pediatric obstructive sleep apnea syndrome. Arch Pediatr Adolesc Med 2005; 159(8):775-785

6. Grunstein R, Wilcox I, Yang TS, Gould Y, Hedner J. Snoring and sleep apnoea in men: association with central obesity and hypertension. Int J Obes Relat Metab Disord 1993;17(9):533-540

7. Wetter DW, Young TB, Bidwell TR, Badr MS, Palta M. Smoking as a risk factor for sleep-disordered breathing. Arch Intern Med 1994;154(19):2219-2224

8. Mitler MM, Dawson A, Henriksen SJ, Sobers M, Bloom FE. Bedtime ethanol increases resistance of upper airways and produces sleep apneas in asymptomatic snorers. Alcohol Clin Exp Res 1988;12(6):801-805

9. Partinen M, Telakivi T. Epidemiology of obstructive sleep apnea syndrome. Sleep 1992;15(6, Suppl):S1-S4

10. Winkelman JW, Goldman H, Piscatelli N, Lukas SE, Dorsey CM, Cunningham S. Are thyroid function tests necessary in patients with suspected sleep apnea? Sleep 1996;19(10):790-793

11. Grunstein RR, Ho KY, Sullivan CE. Sleep apnea in acromegaly. Ann Intern Med 1991;115(7):527-532

12. Leiter JC, Knuth SL, Bartlett DJr. The effect of sleep deprivation on activity of the genioglossus muscle. Am Rev Respir Dis 1985;132(6):1242-1245

13. Liu PY, Yee B, Wishart SM, et al. The short-term effects of high-dose testosterone on sleep, breathing, and function in older men. J Clin Endocrinol Metab 2003;88(8):3605-3613

14. Redline S, Tishler PV. The genetics of sleep apnea. Sleep Med Rev 2000;4(6):583-602

15. Sundquist J, Li X, Friberg D, Hemminki K, Sundquist K. Obstructive sleep apnea syndrome in siblings: an 8-year Swedish follow-up study. Sleep 2008;31(6):817-823

16. Buxbaum SG, Elston RC, Tishler PV, Redline S. Genetics of the apnea hypopnea index in Caucasians and African Americans: I. Segregation analysis. Genet Epidemiol 2002; 22(3):243-253

17. Gislason T, Johannsson JH, Haraldsson A, et al. Familial predisposition and cosegregation analysis of adult obstructive sleep apnea and the sudden infant death syndrome. Am J Respir Crit Care Med 2002;166(6):833-838

18. Friberg D, Sundquist J, Li X, Hemminki K, Sundquist K. Sibling risk of pediatric obstructive sleep apnea syndrome and adenotonsillar hypertrophy. Sleep 2009;32(8):1077-1083

19. Yaggi HK, Concato J, Kernan WN, Lichtman JH, Brass LM, Mohsenin V. Obstructive sleep apnea as a risk factor for stroke and death. N Engl J Med 2005;353(19):2034-2041

20. Marshall NS, Wong KK, Liu PY, Cullen SR, Knuiman MW, Grunstein RR. Sleep apnea as an independent risk factor for all-cause mortality: the Busselton Health Study. Sleep 2008;31(8):1079-1085 
21. McNicholas WT, Bonsigore MR, Bonsignore MR; Management Committee of EU COST ACTION B26. Sleep apnoea as an independent risk factor for cardiovascular disease: current evidence, basic mechanisms and research priorities. Eur Respir J 2007;29(1):156-178

22. Somers VK, White DP, Amin R, et al. Sleep apnea and cardiovascular disease: an American Heart Association/ American College of Cardiology Foundation Scientific Statement from the American Heart Association Council for High Blood Pressure Research Professional Education Committee, Council on Clinical Cardiology, Stroke Council, and Council on Cardiovascular Nursing. J Am Coll Cardiol 2008;52(8):686-717

23. Kiely JL, McNicholas WT. Cardiovascular risk factors in patients with obstructive sleep apnoea syndrome. Eur Respir J 2000;16(1):128-133

24. Aytemir K, Deniz A, Yavuz B, et al. Increased myocardial vulnerability and autonomic nervous system imbalance in obstructive sleep apnea syndrome. Respir Med 2007;101(6): $1277-1282$

25. Ryan S, McNicholas WT. Intermittent hypoxia and activation of inflammatory molecular pathways in OSAS. Arch Physiol Biochem 2008;114(4):261-266

26. Ryan S, Taylor CT, McNicholas WT. Systemic inflammation: a key factor in the pathogenesis of cardiovascular complications in obstructive sleep apnoea syndrome? Thorax 2009;64(7):631-636

27. Attal P, Chanson P. Endocrine aspects of obstructive sleep apnea. J Clin Endocrinol Metab 2010;95(2):483-495

28. Takagi T, Morser J, Gabazza EC, et al. The coagulation and protein $\mathrm{C}$ pathways in patients with sleep apnea. Lung 2009;187(4):209-213

29. Zamarrón C, Ricoy J, Riveiro A, Gude F. Plasminogen activator inhibitor-1 in obstructive sleep apnea patients with and without hypertension. Lung 2008;186(3):151-156

30. Mancia G. Autonomic modulation of the cardiovascular system during sleep. N Eng1 J Med 1993;328(5):347-349

31. Noda A, Yasuma F, Okada T, Yokota M. Influence of movement arousal on circadian rhythm of blood pressure in obstructive sleep apnea syndrome. J Hypertens 2000; 18(5):539-544

32. Weiss JW, Remsburg S, Garpestad E, Ringler J, Sparrow D, Parker JA. Hemodynamic consequences of obstructive sleep apnea. Sleep 1996;19(5):388-397

33. Baguet JP, Barone-Rochette G, Pépin JL. Hypertension and obstructive sleep apnoea syndrome: current perspectives. J Hum Hypertens 2009;23(7):431-443

34. Narkiewicz K, van de Borne PJ, Pesek CA, Dyken ME, Montano N, Somers VK. Selective potentiation of peripheral chemoreflex sensitivity in obstructive sleep apnea. Circulation 1999;99(9):1183-1189

35. Gilmartin GS, Tamisier R, Curley M, Weiss JW. Ventilatory, hemodynamic, sympathetic nervous system, and vascular reactivity changes after recurrent nocturnal sustained hypoxia in humans. Am J Physiol Heart Circ Physiol 2008;295(2):H778-H785

36. Greenberg HE, Sica A, Batson D, Scharf SM. Chronic intermittent hypoxia increases sympathetic responsiveness to hypoxia and hypercapnia. J Appl Physiol 1999;86(1):298-305

37. Morgan BJ, Denahan T, Ebert TJ. Neurocirculatory consequences of negative intrathoracic pressure vs. asphyxia during voluntary apnea. J Appl Physiol 1993;74(6): 2969-2975
38. Sukegawa M, Noda A, Yasuda Y, et al. Impact of microarousal associated with increased negative esophageal pressure in sleep-disordered breathing. Sleep Breath 2009; 13(4):369-373

39. Stradling JR, Pitson DJ, Bennett L, Barbour C, Davies RJ. Variation in the arousal pattern after obstructive events in obstructive sleep apnea. Am J Respir Crit Care Med 1999; 159(1):130-136

40. Davies RJ, Belt PJ, Roberts SJ, Ali NJ, Stradling JR. Arterial blood pressure responses to graded transient arousal from sleep in normal humans. J Appl Physiol 1993;74(3): 1123-1130

41. Brooks D, Horner RL, Kozar LF, Render-Teixeira CL, Phillipson EA. Obstructive sleep apnea as a cause of systemic hypertension. Evidence from a canine model. J Clin Invest 1997;99(1):106-109

42. Kimoff RJ, Makino H, Horner RL, et al. Canine model of obstructive sleep apnea: model description and preliminary application. J Appl Physiol 1994;76(4):1810-1817

43. Fletcher EC, Lesske J, Qian W, Miller CC III, Unger T. Repetitive, episodic hypoxia causes diurnal elevation of blood pressure in rats. Hypertension 1992;19(6 Pt 1): 555-561

44. Guilleminault C, Connolly S, Winkle R, Melvin K, Tilkian A. Cyclical variation of the heart rate in sleep apnoea syndrome. Mechanisms, and usefulness of $24 \mathrm{~h}$ electrocardiography as a screening technique. Lancet 1984;1(8369): 126-131

45. Meanock CI. Influence of the vagus nerve on changes in heart rate during sleep apnoea in man. Clin Sci (Lond) 1982;62(2):163-167

46. Hanly PJ, George CF, Millar TW, Kryger MH. Heart rate response to breath-hold, Valsalva and Mueller maneuvers in obstructive sleep apnea. Chest 1989;95(4):735-739

47. Carlson JT, Hedner J, Elam M, Ejnell H, Sellgren J, Wallin BG. Augmented resting sympathetic activity in awake patients with obstructive sleep apnea. Chest 1993;103(6): 1763-1768

48. Somers VK, Dyken ME, Clary MP, Abboud FM. Sympathetic neural mechanisms in obstructive sleep apnea. J Clin Invest 1995;96(4):1897-1904

49. Narkiewicz K, van de Borne PJ, Cooley RL, Dyken ME, Somers VK. Sympathetic activity in obese subjects with and without obstructive sleep apnea. Circulation 1998;98(8): 772-776

50. Grassi G, Facchini A, Trevano FQ, et al. Obstructive sleep apnea-dependent and -independent adrenergic activation in obesity. Hypertension 2005;46(2):321-325

51. Peled N, Greenberg A, Pillar G, Zinder O, Levi N, Lavie P. Contributions of hypoxia and respiratory disturbance index to sympathetic activation and blood pressure in obstructive sleep apnea syndrome. Am J Hypertens 1998;11(11 Pt 1): 1284-1289

52. Dimsdale JE, Coy T, Ancoli-Israel S, Mills P, Clausen J, Ziegler MG. Sympathetic nervous system alterations in sleep apnea. The relative importance of respiratory disturbance, hypoxia, and sleep quality. Chest 1997;111(3): 639-642

53. Jennum P, Wildschiødtz G, Christensen NJ, Schwartz T. Blood pressure, catecholamines, and pancreatic polypeptide in obstructive sleep apnea with and without nasal Continuous Positive Airway Pressure (nCPAP) treatment. Am J Hypertens 1989;2(11 Pt 1):847-852 
54. Marrone O, Riccobono L, Salvaggio A, Mirabella A, Bonanno A, Bonsignore MR. Catecholamines and blood pressure in obstructive sleep apnea syndrome. Chest 1993; 103(3):722-727

55. Narkiewicz K, van de Borne PJ, Montano N, Dyken ME, Phillips BG, Somers VK. Contribution of tonic chemoreflex activation to sympathetic activity and blood pressure in patients with obstructive sleep apnea. Circulation 1998; 97(10):943-945

56. Narkiewicz K, Pesek CA, Kato M, Phillips BG, Davison DE, Somers VK. Baroreflex control of sympathetic nerve activity and heart rate in obstructive sleep apnea. Hypertension 1998;32(6):1039-1043

57. Leuenberger U, Jacob E, Sweer L, Waravdekar N, Zwillich C, Sinoway L. Surges of muscle sympathetic nerve activity during obstructive apnea are linked to hypoxemia. J Appl Physiol 1995;79(2):581-588

58. Fletcher EC. Effect of episodic hypoxia on sympathetic activity and blood pressure. Respir Physiol 2000;119(2-3): 189-197

59. Parati G, Di Rienzo M, Bonsignore MR, et al. Autonomic cardiac regulation in obstructive sleep apnea syndrome: evidence from spontaneous baroreflex analysis during sleep. J Hypertens 1997;15(12 Pt 2):1621-1626

60. Hedner J, Darpö B, Ejnell H, Carlson J, Caidahl K. Reduction in sympathetic activity after long-term CPAP treatment in sleep apnoea: cardiovascular implications. Eur Respir J 1995;8(2):222-229

61. Veale D, Pépin JL, Wuyam B, Lévy PA. Abnormal autonomic stress responses in obstructive sleep apnoea are reversed by nasal continuous positive airway pressure. Eur Respir J 1996;9(10):2122-2126

62. Narkiewicz K, Kato M, Phillips BG, Pesek CA, Davison DE, Somers VK. Nocturnal continuous positive airway pressure decreases daytime sympathetic traffic in obstructive sleep apnea. Circulation 1999;100(23):2332-2335

63. Gjørup PH, Sadauskiene L, Wessels J, Nyvad O, Strunge B, Pedersen EB. Abnormally increased endothelin-1 in plasma during the night in obstructive sleep apnea: relation to blood pressure and severity of disease. Am J Hypertens 2007; 20(1):44-52

64. Phillips BG, Narkiewicz K, Pesek CA, Haynes WG, Dyken ME, Somers VK. Effects of obstructive sleep apnea on endothelin-1 and blood pressure. J Hypertens 1999;17(1): 61-66

65. Møller DS, Lind P, Strunge B, Pedersen EB. Abnormal vasoactive hormones and 24-hour blood pressure in obstructive sleep apnea. Am J Hypertens 2003;16(4): 274-280

66. Pratt-Ubunama MN, Nishizaka MK, Boedefeld RL, Cofield SS, Harding SM, Calhoun DA. Plasma aldosterone is related to severity of obstructive sleep apnea in subjects with resistant hypertension. Chest 2007;131(2):453-459

67. Calhoun DA, Nishizaka MK, Zaman MA, Harding SM. Aldosterone excretion among subjects with resistant hypertension and symptoms of sleep apnea. Chest 2004; 125(1):112-117

68. Takahashi S, Nakamura Y, Nishijima T, Sakurai S, Inoue $H$. Essential roles of angiotensin II in vascular endothelial growth factor expression in sleep apnea syndrome. Respir Med 2005;99(9):1125-1131

69. Svatikova A, Olson LJ, Wolk R, et al. Obstructive sleep apnea and aldosterone. Sleep 2009;32(12):1589-1592
70. Grassi G, Seravalle G, Quarti-Trevano F, et al. Reinforcement of the adrenergic overdrive in the metabolic syndrome complicated by obstructive sleep apnea. J Hypertens 2010; 28(6):1313-1320

71. Steiropoulos P, Papanas N, Nena E, et al. Markers of glycemic control and insulin resistance in non-diabetic patients with Obstructive Sleep Apnea Hypopnea Syndrome: does adherence to CPAP treatment improve glycemic control?. Sleep Med 2009;10(8):887-891

72. Lam DC, Xu A, Lam KS, et al. Serum adipocyte-fatty acid binding protein level is elevated in severe OSA and correlates with insulin resistance. Eur Respir J 2009;33(2):346-351

73. Cuhadaroğlu C, Utkusava A, Oztürk L, Salman S, Ece T. Effects of nasal CPAP treatment on insulin resistance, lipid profile, and plasma leptin in sleep apnea. Lung 2009; 187(2):75-81

74. Lam JC, Xu A, Tam S, et al. Hypoadiponectinemia is related to sympathetic activation and severity of obstructive sleep apnea. Sleep 2008;31(12):1721-1727

75. Botros N, Concato J, Mohsenin V, Selim B, Doctor K, Yaggi HK. Obstructive sleep apnea as a risk factor for type 2 diabetes. Am J Med 2009;122(12):1122-1127

76. Ronksley PE, Hemmelgarn BR, Heitman SJ, et al. Obstructive sleep apnoea is associated with diabetes in sleepy subjects. Thorax 2009;64(10):834-839

77. Carneiro G, Togeiro SM, Ribeiro-Filho FF, et al Continuous positive airway pressure therapy improves hypoadiponectinemia in severe obese men with obstructive sleep apnea without changes in insulin resistance. Metab Syndr Relat Disord 2009;7(6):537-542

78. Dawson A, Abel SL, Loving RT, et al. CPAP therapy of obstructive sleep apnea in type 2 diabetics improves glycemic control during sleep. J Clin Sleep Med 2008;4(6):538-542

79. Louis M, Punjabi NM. Effects of acute intermittent hypoxia on glucose metabolism in awake healthy volunteers. J Appl Physiol 2009;106(5):1538-1544

80. Coughlin SR, Mawdsley L, Mugarza JA, Calverley PM, Wilding JP. Obstructive sleep apnoea is independently associated with an increased prevalence of metabolic syndrome. Eur Heart J 2004;25(9):735-741

81. Li AM, $\mathrm{Ng} \mathrm{C}, \mathrm{Ng} \mathrm{SK}$, et al. Adipokines in children with obstructive sleep apnea and the effects of treatment. Chest 2010;137(3):529-535

82. Tokuda F, Sando Y, Matsui H, Koike H, Yokoyama T. Serum levels of adipocytokines, adiponectin and leptin, in patients with obstructive sleep apnea syndrome. Intern Med 2008;47(21):1843-1849

83. Drummond M, Winck JC, Guimarães JT, Santos AC, Almeida J, Marques JA. Autoadjusting-CPAP effect on serum leptin concentrations in obstructive sleep apnoea patients. BMC Pulm Med 2008;8:21

84. Trenell MI, Ward JA, Yee BJ, et al. Influence of constant positive airway pressure therapy on lipid storage, muscle metabolism and insulin action in obese patients with severe obstructive sleep apnoea syndrome. Diabetes Obes Metab 2007;9(5):679-687

85. Tatsumi K, Kasahara Y, Kurosu K, Tanabe N, Takiguchi Y, Kuriyama T. Sleep oxygen desaturation and circulating leptin in obstructive sleep apnea-hypopnea syndrome. Chest 2005;127(3):716-721

86. Shimura R, Tatsumi K, Nakamura A, et al. Fat accumulation, leptin, and hypercapnia in obstructive sleep apneahypopnea syndrome. Chest 2005;127(2):543-549 
87. Sanner BM, Kollhosser P, Buechner N, Zidek W, Tepel M. Influence of treatment on leptin levels in patients with obstructive sleep apnoea. Eur Respir J 2004;23(4):601-604

88. Harsch IA, Konturek PC, Koebnick C, et al. Leptin and ghrelin levels in patients with obstructive sleep apnoea: effect of CPAP treatment. Eur Respir J 2003;22(2):251-257

89. Schäfer H, Pauleit D, Sudhop T, Gouni-Berthold I, Ewig S, Berthold HK. Body fat distribution, serum leptin, and cardiovascular risk factors in men with obstructive sleep apnea. Chest 2002;122(3):829-839

90. Shimizu K, Chin K, Nakamura T, et al. Plasma leptin levels and cardiac sympathetic function in patients with obstructive sleep apnoea-hypopnoea syndrome. Thorax 2002;57(5): 429-434

91. Ip MS, Lam KS, Ho C, Tsang KW, Lam W. Serum leptin and vascular risk factors in obstructive sleep apnea. Chest 2000;118(3):580-586

92. Phillips BG, Kato M, Narkiewicz K, Choe I, Somers VK. Increases in leptin levels, sympathetic drive, and weight gain in obstructive sleep apnea. Am J Physiol Heart Circ Physiol 2000;279(1):H234-H237

93. Chin K, Shimizu K, Nakamura T, et al. Changes in intraabdominal visceral fat and serum leptin levels in patients with obstructive sleep apnea syndrome following nasal continuous positive airway pressure therapy. Circulation 1999;100(7):706-712

94. Arnardottir ES, Mackiewicz M, Gislason T, Teff KL, Pack AI. Molecular signatures of obstructive sleep apnea in adults: a review and perspective. Sleep 2009;32(4):447-470

95. Kheirandish L, Row BW, Li RC, Brittian KR, Gozal D. Apolipoprotein E-deficient mice exhibit increased vulnerability to intermittent hypoxia-induced spatial learning deficits. Sleep 2005;28(11):1412-1417

96. Prabhakar NR, Kumar GK, Nanduri J, Semenza GL. ROS signaling in systemic and cellular responses to chronic intermittent hypoxia. Antioxid Redox Signal 2007;9(9): 1397-1403

97. Row BW, Liu R, Xu W, Kheirandish L, Gozal D. Intermittent hypoxia is associated with oxidative stress and spatial learning deficits in the rat. Am J Respir Crit Care Med 2003;167(11):1548-1553

98. Zhan G, Serrano F, Fenik P, et al. NADPH oxidase mediates hypersomnolence and brain oxidative injury in a murine model of sleep apnea. Am J Respir Crit Care Med 2005;172(7):921-929

99. Montgomery-Downs HE, Krishna J, Roberts LJ II, Gozal D. Urinary F2-isoprostane metabolite levels in children with sleep-disordered breathing. Sleep Breath 2006;10(4): 211-215

100. Barceló A, Barbé F, de la Peña M, et al. Antioxidant status in patients with sleep apnoea and impact of continuous positive airway pressure treatment. Eur Respir J 2006; 27(4):756-760

101. Carpagnano GE, Kharitonov SA, Resta O, FoschinoBarbaro MP, Gramiccioni E, Barnes PJ. 8-Isoprostane, a marker of oxidative stress, is increased in exhaled breath condensate of patients with obstructive sleep apnea after night and is reduced by continuous positive airway pressure therapy. Chest 2003;124(4):1386-1392

102. Dyugovskaya L, Lavie P, Lavie L. Increased adhesion molecules expression and production of reactive oxygen species in leukocytes of sleep apnea patients. Am J Respir Crit Care Med 2002;165(7):934-939
103. Jordan W, Cohrs S, Degner D, et al. Evaluation of oxidative stress measurements in obstructive sleep apnea syndrome. J Neural Transm 2006;113(2):239-254

104. Schulz R, Mahmoudi S, Hattar K, et al. Enhanced release of superoxide from polymorphonuclear neutrophils in obstructive sleep apnea. Impact of continuous positive airway pressure therapy. Am J Respir Crit Care Med 2000;162(2 Pt 1): 566-570

105. Yamauchi M, Nakano H, Maekawa J, et al. Oxidative stress in obstructive sleep apnea. Chest 2005;127(5):1674-1679

106. Dorkova Z, Petrasova D, Molcanyiova A, Popovnakova M, Tkacova R. Effects of continuous positive airway pressure on cardiovascular risk profile in patients with severe obstructive sleep apnea and metabolic syndrome. Chest 2008;134(4): 686-692

107. de Lima AM, Franco CM, de Castro CM, Bezerra AD, Atade L, Halpern A. Effects of nasal continuous positive airway pressure treatment on oxidative stress and adiponectin levels in obese patients with obstructive sleep apnea. Respiration 2009; July 3(Epub ahead of print)

108. Gozal D, Serpero LD, Sans Capdevila O, KheirandishGozal L. Systemic inflammation in non-obese children with obstructive sleep apnea. Sleep Med 2008;9(3):254-259

109. Punjabi NM, Beamer BA. C-reactive protein is associated with sleep disordered breathing independent of adiposity. Sleep 2007;30(1):29-34

110. Tauman R, O’Brien LM, Gozal D. Hypoxemia and obesity modulate plasma $\mathrm{C}$-reactive protein and interleukin-6 levels in sleep-disordered breathing. Sleep Breath 2007;11(2):77-84

111. Ursava A, Karadağ M, Rodoplu E, Yilmaztepe A, Oral HB, Gözü RO. Circulating ICAM-1 and VCAM-1 levels in patients with obstructive sleep apnea syndrome. Respiration 2007;74(5):525-532

112. Kobayashi K, Nishimura Y, Shimada T, et al. Effect of continuous positive airway pressure on soluble CD40 ligand in patients with obstructive sleep apnea syndrome. Chest 2006;129(3):632-637

113. Dyugovskaya L, Lavie P, Lavie L. Lymphocyte activation as a possible measure of atherosclerotic risk in patients with sleep apnea. Ann N Y Acad Sci 2005;1051:340-350

114. Minoguchi K, Tazaki T, Yokoe T, et al. Elevated production of tumor necrosis factor-alpha by monocytes in patients with obstructive sleep apnea syndrome. Chest 2004;126(5):1473-1479

115. Ciftci TU, Kokturk O, Bukan N, Bilgihan A. The relationship between serum cytokine levels with obesity and obstructive sleep apnea syndrome. Cytokine 2004;28(2): $87-91$

116. Teramoto S, Yamamoto H, Ouchi Y. Increased plasma interleukin-6 is associated with the pathogenesis of obstructive sleep apnea syndrome. Chest 2004;125(5): 1964-1965; author reply 1965

117. Thomopoulos C, Tsioufis C, Dimitriadis K, et al. Obstructive sleep apnoea syndrome is associated with enhanced sub-clinical inflammation and asymmetric dimethyl-arginine levels in hypertensives. J Hum Hypertens 2009;23(1):65-67

118. Arias MA, García-Río F, Alonso-Fernández A, et al. CPAP decreases plasma levels of soluble tumour necrosis factor-alpha receptor 1 in obstructive sleep apnoea. Eur Respir J 2008;32(4):1009-1015

119. Sahlman J, Miettinen K, Peuhkurinen K, et al; Kuopio Sleep Apnoea Group. The activation of the inflammatory 
cytokines in overweight patients with mild obstructive sleep apnoea. J Sleep Res 2010;19(2):341-348

120. Tamaki S, Yamauchi M, Fukuoka A, et al. Production of inflammatory mediators by monocytes in patients with obstructive sleep apnea syndrome. Intern Med 2009;48(15): 1255-1262

121. Schulz R, Hummel C, Heinemann S, Seeger W, Grimminger F. Serum levels of vascular endothelial growth factor are elevated in patients with obstructive sleep apnea and severe nighttime hypoxia. Am J Respir Crit Care Med 2002;165(1):67-70

122. Imagawa S, Yamaguchi $Y$, Higuchi M, et al. Levels of vascular endothelial growth factor are elevated in patients with obstructive sleep apnea-hypopnea syndrome. Blood 2001;98(4):1255-1257

123. Teramoto S, Kume $\mathrm{H}$, Yamamoto $\mathrm{H}$, et al. Effects of oxygen administration on the circulating vascular endothelial growth factor (VEGF) levels in patients with obstructive sleep apnea syndrome. Intern Med 2003;42(8):681-685

124. Kähler CM, Wechselberger J, Molnar C, Prior C. Serum levels of vascular endothelial growth factor are elevated in patients with obstructive sleep apnea and severe night time hypoxia. Am J Respir Crit Care Med 2003;167(1):92-93; author reply 93

125. Gozal D, Lipton AJ, Jones KL. Circulating vascular endothelial growth factor levels in patients with obstructive sleep apnea. Sleep 2002;25(1):59-65

126. Gunsilius E, Petzer AL, Gastl GA. Blood levels of vascular endothelial growth factor in obstructive sleep apneahypopnea syndrome. Blood 2002;99(1):393-394

127. Kohler M, Ayers L, Pepperell JC, et al. Effects of continuous positive airway pressure on systemic inflammation in patients with moderate to severe obstructive sleep apnoea: a randomised controlled trial. Thorax 2009;64(1): $67-73$

128. Vgontzas AN, Zoumakis E, Bixler EO, et al. Selective effects of CPAP on sleep apnoea-associated manifestations. Eur J Clin Invest 2008;38(8):585-595

129. Vgontzas AN, Zoumakis E, Lin HM, Bixler EO, Trakada G, Chrousos GP. Marked decrease in sleepiness in patients with sleep apnea by etanercept, a tumor necrosis factoralpha antagonist. J Clin Endocrinol Metab 2004;89(9): 4409-4413

130. Barceló A, de la Peña M, Ayllón O, et al. Increased plasma levels of asymmetric dimethylarginine and soluble CD40 ligand in patients with sleep apnea. Respiration 2009;77(1): $85-90$

131. Akinnusi ME, Paasch LL, Szarpa KR, Wallace PK, El Solh AA. Impact of nasal continuous positive airway pressure therapy on markers of platelet activation in patients with obstructive sleep apnea. Respiration 2009;77(1):25-31

132. Cox D, Bradford A. Continuous positive airway pressure and platelet activation in obstructive sleep apnoea. Respiration 2009;77(1):18-20

133. Kraiczi H, Caidahl K, Samuelsson A, Peker Y, Hedner J. Impairment of vascular endothelial function and left ventricular filling : association with the severity of apnea-induced hypoxemia during sleep. Chest 2001;119(4):1085-1091

134. Kato M, Roberts-Thomson P, Phillips BG, et al. Impairment of endothelium-dependent vasodilation of resistance vessels in patients with obstructive sleep apnea. Circulation 2000;102(21):2607-2610
135. Oflaz H, Cuhadaroglu C, Pamukcu B, et al. Endothelial function in patients with obstructive sleep apnea syndrome but without hypertension. Respiration 2006;73(6):751-756

136. Tanriverdi H, Evrengul H, Kara CO, et al. Aortic stiffness, flow-mediated dilatation and carotid intima-media thickness in obstructive sleep apnea: non-invasive indicators of atherosclerosis. Respiration 2006;73(6):741-750

137. Gozal D, Kheirandish-Gozal L, Serpero LD, Sans Capdevila $\mathrm{O}$, Dayyat E. Obstructive sleep apnea and endothelial function in school-aged nonobese children: effect of adenotonsillectomy. Circulation 2007;116(20):2307-2314

138. Chung S, Yoon IY, Shin YK, et al. Endothelial dysfunction and $\mathrm{C}$-reactive protein in relation with the severity of obstructive sleep apnea syndrome. Sleep 2007;30(8): 997-1001

139. Carlson JT, Rångemark $\mathrm{C}$, Hedner JA. Attenuated endothelium-dependent vascular relaxation in patients with sleep apnoea. J Hypertens 1996;14(5):577-584

140. Duchna HW, Orth M, Schultze-Werninghaus G, Guilleminault C, Stoohs RA. Long-term effects of nasal continuous positive airway pressure on vasodilatory endothelial function in obstructive sleep apnea syndrome. Sleep Breath 2005;9(3):97-103

141. Cross MD, Mills NL, Al-Abri M, et al. Continuous positive airway pressure improves vascular function in obstructive sleep apnoea/hypopnoea syndrome: a randomised controlled trial. Thorax 2008;63(7):578-583

142. Ohike Y, Kozaki K, Iijima K, et al. Amelioration of vascular endothelial dysfunction in obstructive sleep apnea syndrome by nasal continuous positive airway pressure-possible involvement of nitric oxide and asymmetric NG, NGdimethylarginine. Circ J 2005;69(2):221-226

143. Lattimore JL, Wilcox I, Skilton M, Langenfeld M, Celermajer DS. Treatment of obstructive sleep apnoea leads to improved microvascular endothelial function in the systemic circulation. Thorax 2006;61(6):491-495

144. Comondore VR, Cheema R, Fox J, et al. The impact of CPAP on cardiovascular biomarkers in minimally symptomatic patients with obstructive sleep apnea: a pilot feasibility randomized crossover trial. Lung 2009;187(1):17-22

145. Itzhaki S, Dorchin H, Clark G, Lavie L, Lavie P, Pillar G. The effects of 1 -year treatment with a herbst mandibular advancement splint on obstructive sleep apnea, oxidative stress, and endothelial function. Chest 2007;131(3):740-749

146. Duchna HW, Orth M, Schultze-Werninghaus G, Guilleminault C, Stoohs RA. Antihypertensive treatment and endothelium-dependent venodilation in sleep-disordered breathing. Sleep Breath 2006;10(3):115-122

147. Grebe M, Eisele HJ, Weissmann N, et al. Antioxidant vitamin $\mathrm{C}$ improves endothelial function in obstructive sleep apnea. Am J Respir Crit Care Med 2006;173(8):897-901

148. El Solh AA, Saliba R, Bosinski T, Grant BJ, Berbary E, Miller N. Allopurinol improves endothelial function in sleep apnoea: a randomised controlled study. Eur Respir J 2006; 27(5):997-1002

149. Zhong X, Xiao Y, Basner RC. Effects of antihypertensives on arterial responses associated with obstructive sleep apneas. Chin Med J (Engl) 2005;118(2):123-129

150. Protogerou AD, Laaban JP, Czernichow S, et al. Structural and functional arterial properties in patients with obstructive sleep apnoea syndrome and cardiovascular comorbidities. J Hum Hypertens 2008;22(6):415-422 
151. Kohler M, Craig S, Nicoll D, Leeson P, Davies RJ, Stradling JR. Endothelial function and arterial stiffness in minimally symptomatic obstructive sleep apnea. Am J Respir Crit Care Med 2008;178(9):984-988

152. Drager LF, Diegues-Silva L, Diniz PM, et al. Obstructive sleep apnea, masked hypertension, and arterial stiffness in men. Am J Hypertens 2010;23(3):249-254

153. Suzuki T, Nakano H, Maekawa J, et al. Obstructive sleep apnea and carotid-artery intima-media thickness. Sleep 2004;27(1):129-133

154. Baguet JP, Hammer L, Lévy P, et al. The severity of oxygen desaturation is predictive of carotid wall thickening and plaque occurrence. Chest 2005;128(5):3407-3412

155. Minoguchi K, Yokoe T, Tazaki T, et al. Increased carotid intima-media thickness and serum inflammatory markers in obstructive sleep apnea. Am J Respir Crit Care Med 2005; 172(5):625-630

156. Drager LF, Bortolotto LA, Krieger EM, Lorenzi-Filho G. Additive effects of obstructive sleep apnea and hypertension on early markers of carotid atherosclerosis. Hypertension 2009;53(1):64-69

157. Lavie L, Perelman A, Lavie P. Plasma homocysteine levels in obstructive sleep apnea: association with cardiovascular morbidity. Chest 2001;120(3):900-908

158. Ozkan Y, Firat H, Simek B, Torun M, Yardim-Akaydin S. Circulating nitric oxide (NO), asymmetric dimethylarginine (ADMA), homocysteine, and oxidative status in obstructive sleep apnea-hypopnea syndrome (OSAHS). Sleep Breath 2008;12(2):149-154

159. Takagi T, Morser J, Gabazza EC, et al. The coagulation and protein $\mathrm{C}$ pathways in patients with sleep apnea. Lung 2009;187(4):209-213

160. von Känel R, Le DT, Nelesen RA, Mills PJ, Ancoli-Israel S, Dimsdale JE. The hypercoagulable state in sleep apnea is related to comorbid hypertension. J Hypertens 2001;19(8): 1445-1451

161. von Känel R, Loredo JS, Ancoli-Israel S, Dimsdale JE. Association between sleep apnea severity and blood coagulability: Treatment effects of nasal continuous positive airway pressure. Sleep Breath 2006;10(3):139-146

162. von Känel R, Loredo JS, Powell FL, Adler KA, Dimsdale JE. Short-term isocapnic hypoxia and coagulation activation in patients with sleep apnea. Clin Hemorheol Microcirc 2005;33(4):369-377

163. Steiner S, Jax T, Evers S, Hennersdorf M, Schwalen A, Strauer BE. Altered blood rheology in obstructive sleep apnea as a mediator of cardiovascular risk. Cardiology 2005;104(2):92-96

164. Ishikawa J, Hoshide S, Eguchi K, et al. Increased low-grade inflammation and plasminogen-activator inhibitor-1 level in nondippers with sleep apnea syndrome. J Hypertens 2008; 26(6):1181-1187

165. Zamarrón C, Ricoy J, Riveiro A, Gude F. Plasminogen activator inhibitor-1 in obstructive sleep apnea patients with and without hypertension. Lung 2008;186(3):151-156

166. Riha RL. Genetic aspects of the obstructive sleep apnoea/ hypopnoea syndrome-is there a common link with obesity?. Respiration 2009;78(1):5-17

167. Doi M, Takahashi Y, Komatsu R, et al. Salt-sensitive hypertension in circadian clock-deficient Cry-null mice involves dysregulated adrenal Hsd3b6. Nat Med 2010; 16(1):67-74
168. Portaluppi F, Provini F, Cortelli P, et al. Undiagnosed sleep-disordered breathing among male nondippers with essential hypertension. J Hypertens 1997;15(11):1227-1233

169. Stoohs RA, Gingold J, Cohrs S, Harter R, Finlayson E, Guilleminault C. Sleep-disordered breathing and systemic hypertension in the older male. J Am Geriatr Soc 1996; 44(11):1295-1300

170. Fletcher EC, DeBehnke RD, Lovoi MS, Gorin AB. Undiagnosed sleep apnea in patients with essential hypertension. Ann Intern Med 1985;103(2):190-195

171. Logan AG, Perlikowski SM, Mente A, et al. High prevalence of unrecognized sleep apnoea in drug-resistant hypertension. J Hypertens 2001;19(12):2271-2277

172. Gonçalves SC, Martinez D, Gus M, et al. Obstructive sleep apnea and resistant hypertension: a case-control study. Chest 2007;132(6):1858-1862

173. Chobanian AV, Bakris GL, Black HR, et al; Joint National Committee on Prevention, Detection, Evaluation, and Treatment of High Blood Pressure. National Heart, Lung, and Blood Institute; National High Blood Pressure Education Program Coordinating Committee. Seventh report of the joint national committee on prevention, detection, evaluation, and treatment of high blood pressure. Hypertension 2003;42(6):1206-1252

174. Tishler PV, Larkin EK, Schluchter MD, Redline S. Incidence of sleep-disordered breathing in an urban adult population: the relative importance of risk factors in the development of sleep-disordered breathing. JAMA 2003; 289(17):2230-2237

175. Newman AB, Foster G, Givelber R, Nieto FJ, Redline S, Young T. Progression and regression of sleep-disordered breathing with changes in weight: the Sleep Heart Health Study. Arch Intern Med 2005;165(20):2408-2413

176. Nieto FJ, Young TB, Lind BK, et al. Association of sleepdisordered breathing, sleep apnea, and hypertension in a large community-based study. Sleep Heart Health Study. JAMA 2000;283(14):1829-1836

177. O'Connor GT, Caffo B, Newman AB, et al. Prospective study of sleep-disordered breathing and hypertension: the Sleep Heart Health Study. Am J Respir Crit Care Med 2009;179(12):1159-1164

178. Peppard PE, Young T, Palta M, Skatrud J. Prospective study of the association between sleep-disordered breathing and hypertension. N Engl J Med 2000;342(19):1378-1384

179. Bixler EO, Vgontzas AN, Lin HM, et al. Association of hypertension and sleep-disordered breathing. Arch Intern Med 2000;160(15):2289-2295

180. Haas DC, Foster GL, Nieto FJ, et al. Age-dependent associations between sleep-disordered breathing and hypertension: importance of discriminating between systolic/diastolic hypertension and isolated systolic hypertension in the Sleep Heart Health Study. Circulation 2005;111(5):614-621

181. Bixler EO, Vgontzas AN, Lin HM, et al. Blood pressure associated with sleep-disordered breathing in a population sample of children. Hypertension 2008;52(5):841-846

182. Davies CW, Crosby JH, Mullins RL, Barbour C, Davies RJ, Stradling JR. Case-control study of 24 hour ambulatory blood pressure in patients with obstructive sleep apnoea and normal matched control subjects. Thorax 2000;55(9):736-740

183. Suzuki M, Guilleminault C, Otsuka K, Shiomi T. Blood pressure "dipping" and "non-dipping" in obstructive sleep apnea syndrome patients. Sleep 1996;19(5):382-387 
184. Coca A. Circadian rhythm and blood pressure control: physiological and pathophysiological factors. J Hypertens Suppl 1994;12(5):S13-S21

185. Ancoli-Israel S, Stepnowsky C, Dimsdale J, Marler M, Cohen-Zion M, Johnson S. The effect of race and sleepdisordered breathing on nocturnal BP "dipping": analysis in an older population. Chest 2002;122(4):1148-1155

186. Noda A, Okada T, Hayashi H, Yasuma F, Yokota M. 24hour ambulatory blood pressure variability in obstructive sleep apnea syndrome. Chest 1993;103(5):1343-1347

187. Baguet J-P, Lévy P, Barone-Rochette G, et al. Masked hypertension in obstructive sleep apnea syndrome. J Hypertens 2008;26(5):885-892

188. Narkiewicz K, Montano N, Cogliati C, van de Borne PJ, Dyken ME, Somers VK. Altered cardiovascular variability in obstructive sleep apnea. Circulation 1998;98(11): 1071-1077

189. Baguet J-P, Hammer L, Lévy P, et al. Night-time and diastolic hypertension are common and underestimated conditions in newly diagnosed apnoeic patients. J Hypertens 2005;23(3):521-527

190. Barbé F, Mayoralas LR, Duran J, et al. Treatment with continuous positive airway pressure is not effective in patients with sleep apnea but no daytime sleepiness. a randomized, controlled trial. Ann Intern Med 2001; 134(11):1015-1023

191. Barnes M, Houston D, Worsnop CJ, et al. A randomized controlled trial of continuous positive airway pressure in mild obstructive sleep apnea. Am J Respir Crit Care Med 2002;165(6):773-780

192. Becker HF, Jerrentrup A, Ploch T, et al. Effect of nasal continuous positive airway pressure treatment on blood pressure in patients with obstructive sleep apnea. Circulation 2003;107(1):68-73

193. Campos-Rodriguez F, Grilo-Reina A, Perez-Ronchel J, et al. Effect of continuous positive airway pressure on ambulatory BP in patients with sleep apnea and hypertension: a placebo-controlled trial. Chest 2006;129(6): 1459-1467

194. Coughlin SR, Mawdsley L, Mugarza JA, Wilding JP, Calverley PM. Cardiovascular and metabolic effects of CPAP in obese males with OSA. Eur Respir J 2007; 29(4):720-727

195. Dimsdale JE, Loredo JS, Profant J. Effect of continuous positive airway pressure on blood pressure : a placebo trial. Hypertension 2000;35(1 Pt 1):144-147

196. Faccenda JF, Mackay TW, Boon NA, Douglas NJ. Randomized placebo-controlled trial of continuous positive airway pressure on blood pressure in the sleep apneahypopnea syndrome. Am J Respir Crit Care Med 2001; 163(2):344-348

197. Norman D, Loredo JS, Nelesen RA, et al. Effects of continuous positive airway pressure versus supplemental oxygen on 24-hour ambulatory blood pressure. Hypertension 2006;47(5):840-845

198. Pepperell JC, Ramdassingh-Dow S, Crosthwaite N, et al. Ambulatory blood pressure after therapeutic and subtherapeutic nasal continuous positive airway pressure for obstructive sleep apnoea: a randomised parallel trial. Lancet 2002;359(9302):204-210

199. Robinson GV, Smith DM, Langford BA, Davies RJ, Stradling JR. Continuous positive airway pressure does not reduce blood pressure in nonsleepy hypertensive OSA patients. Eur Respir J 2006;27(6):1229-1235

200. Usui K, Bradley TD, Spaak J, et al. Inhibition of awake sympathetic nerve activity of heart failure patients with obstructive sleep apnea by nocturnal continuous positive airway pressure. J Am Coll Cardiol 2005;45(12):2008-2011

201. Arias MA, García-Río F, Alonso-Fernández A, Mediano O, Martínez I, Villamor J. Obstructive sleep apnea syndrome affects left ventricular diastolic function: effects of nasal continuous positive airway pressure in men. Circulation 2005;112(3):375-383

202. Barnes M, McEvoy RD, Banks S, et al. Efficacy of positive airway pressure and oral appliance in mild to moderate obstructive sleep apnea. Am J Respir Crit Care Med 2004; 170(6):656-664

203. Engleman HM, Gough K, Martin SE, Kingshott RN, Padfield PL, Douglas NJ. Ambulatory blood pressure on and off continuous positive airway pressure therapy for the sleep apnea/hypopnea syndrome: effects in "non-dippers". Sleep 1996;19(5):378-381

204. Ip MS, Tse HF, Lam B, Tsang KW, Lam WK. Endothelial function in obstructive sleep apnea and response to treatment. Am J Respir Crit Care Med 2004;169(3):348-353

205. Kaneko Y, Floras JS, Usui K, et al. Cardiovascular effects of continuous positive airway pressure in patients with heart failure and obstructive sleep apnea. N Engl J Med 2003; 348(13):1233-1241

206. Mansfield DR, Gollogly NC, Kaye DM, Richardson M, Bergin P, Naughton MT. Controlled trial of continuous positive airway pressure in obstructive sleep apnea and heart failure. Am J Respir Crit Care Med 2004;169(3):361-366

207. Mills PJ, Kennedy BP, Loredo JS, Dimsdale JE, Ziegler MG. Effects of nasal continuous positive airway pressure and oxygen supplementation on norepinephrine kinetics and cardiovascular responses in obstructive sleep apnea. J Appl Physiol 2006;100(1):343-348

208. Alajmi M, Mulgrew AT, Fox J, et al. Impact of continuous positive airway pressure therapy on blood pressure in patients with obstructive sleep apnea hypopnea: a metaanalysis of randomized controlled trials. Lung 2007;185(2): $67-72$

209. Haentjens P, Van Meerhaeghe A, Moscariello A, et al. The impact of continuous positive airway pressure on blood pressure in patients with obstructive sleep apnea syndrome: evidence from a meta-analysis of placebo-controlled randomized trials. Arch Intern Med 2007;167(8):757-764

210. Bazzano LA, Khan Z, Reynolds K, He J. Effect of nocturnal nasal continuous positive airway pressure on blood pressure in obstructive sleep apnea. Hypertension 2007;50(2): 417-423

211. Akashiba T, Minemura H, Yamamoto H, Kosaka N, Saito O, Horie T. Nasal continuous positive airway pressure changes blood pressure "non-dippers" to "dippers" in patients with obstructive sleep apnea. Sleep 1999;22(7): 849-853

212. Hermida RC, Zamarrón C, Ayala DE, Calvo C. Effect of continuous positive airway pressure on ambulatory blood pressure in patients with obstructive sleep apnoea. Blood Press Monit 2004;9(4):193-202

213. Gotsopoulos H, Kelly JJ, Cistulli PA. Oral appliance therapy reduces blood pressure in obstructive sleep apnea: a randomized, controlled trial. Sleep 2004;27(5):934-941 
214. Kraiczi H, Hedner J, Peker Y, Grote L. Comparison of atenolol, amlodipine, enalapril, hydrochlorothiazide, and losartan for antihypertensive treatment in patients with obstructive sleep apnea. Am J Respir Crit Care Med 2000; 161(5):1423-1428

215. Wustmann K, Kucera JP, Scheffers I, et al. Effects of chronic baroreceptor stimulation on the autonomic cardiovascular regulation in patients with drug-resistant arterial hypertension. Hypertension 2009;54(3):530-536

216. Arzt M, Young T, Finn L, Skatrud JB, Bradley TD. Association of sleep-disordered breathing and the occurrence of stroke. Am J Respir Crit Care Med 2005;172: 1447-1451

217. Elwood P, Hack M, Pickering J, Hughes J, Gallacher J. Sleep disturbance, stroke, and heart disease events: evidence from the Caerphilly cohort. J Epidemiol Community Health 2006;60(1):69-73

218. Mohsenin V, Valor R. Sleep apnea in patients with hemispheric stroke. Arch Phys Med Rehabil 1995;76(1): 71-76

219. Dyken ME, Somers VK, Yamada T, Ren ZY, Zimmerman $\mathrm{MB}$. Investigating the relationship between stroke and obstructive sleep apnea. Stroke 1996;27(3):401-407

220. Shahar E, Whitney CW, Redline S, et al. Sleep-disordered breathing and cardiovascular disease: cross-sectional results of the Sleep Heart Health Study. Am J Respir Crit Care Med 2001;163(1):19-25

221. Good DC, Henkle JQ, Gelber D, Welsh J, Verhulst S. Sleep-disordered breathing and poor functional outcome after stroke. Stroke 1996;27(2):252-259

222. Sahlin C, Sandberg O, Gustafson Y, et al. Obstructive sleep apnea is a risk factor for death in patients with stroke: a 10year follow-up. Arch Intern Med 2008;168(3):297-301

223. Palomäki H. Snoring and the risk of ischemic brain infarction. Stroke 1991;22(8):1021-1025

224. Neau J-Ph, Meurice JC, Paquereau J, Chavagnat JJ, Ingrand P, Gil R. Habitual snoring as a risk factor for brain infarction. Acta Neurol Scand 1995;92(1):63-68

225. Askenasy JJM, Goldhammer I. Sleep apnea as a feature of bulbar stroke. Stroke 1988;19(5):637-639

226. Bogousslavsky J, Khurana R, Deruaz JP, et al. Respiratory failure and unilateral caudal brainstem infarction. Ann Neurol 1990;28(5):668-673

227. Droste DW, Lüdemann P, Anders F, et al. Middle cerebral artery blood flow velocity, end-tidal pCO2 and blood pressure in patients with obstructive sleep apnea and in healthy subjects during continuous positive airway pressure breathing. Neurol Res 1999;21(8):737-741

228. Diomedi M, Placidi F, Cupini LM, Bernardi G, Silvestrini M. Cerebral hemodynamic changes in sleep apnea syndrome and effect of continuous positive airway pressure treatment. Neurology 1998;51(4):1051-1056

229. Hajak G, Klingelhöfer J, Schulz-Varszegi M, Sander D, Rüther E. Sleep apnea syndrome and cerebral hemodynamics. Chest 1996;110(3):670-679

230. Dikmenoğlu N, Ciftçi B, Ileri E, et al. Erythrocyte deformability, plasma viscosity and oxidative status in patients with severe obstructive sleep apnea syndrome. Sleep Med 2006;7(3):255-261

231. Furtner M, Staudacher M, Frauscher B, et al. Cerebral vasoreactivity decreases overnight in severe obstructive sleep apnea syndrome: a study of cerebral hemodynamics. Sleep Med 2009;10(8):875-881
232. Altin R, Ozdemir H, Mahmutyazicioğlu K, et al. Evaluation of carotid artery wall thickness with high-resolution sonography in obstructive sleep apnea syndrome. J Clin Ultrasound 2005;33(2):80-86

233. Beelke M, Angeli S, Del Sette M, et al. Prevalence of patent foramen ovale in subjects with obstructive sleep apnea: a transcranial Doppler ultrasound study. Sleep Med 2003; 4(3):219-223

234. Wessendorf TE, Thilmann AF, Wang YM, Schreiber A, Konietzko N, Teschler H. Fibrinogen levels and obstructive sleep apnea in ischemic stroke. Am J Respir Crit Care Med 2000;162(6):2039-2042

235. Geiser T, Buck F, Meyer BJ, Bassetti C, Haeberli A, Gugger M. In vivo platelet activation is increased during sleep in patients with obstructive sleep apnea syndrome. Respiration 2002;69(3):229-234

236. Bokinsky G, Miller M, Ault K, Husband P, Mitchell J. Spontaneous platelet activation and aggregation during obstructive sleep apnea and its response to therapy with nasal continuous positive airway pressure. A preliminary investigation. Chest 1995;108(3):625-630

237. Hedner J, Carlson J, Rangemark C, Gleerup G, Wither K. Platelet function and fibrinolytic activity in patients with sleep apnoea. J Sleep Res 1994;3(Suppl 1):101

238. Sandberg O, Franklin KA, Bucht G, Eriksson S, Gustafson $Y$. Nasal continuous positive airway pressure in stroke patients with sleep apnoea: a randomized treatment study. Eur Respir J 2001;18(4):630-634

239. Hsu CY, Vennelle M, Li HY, Engleman HM, Dennis MS, Douglas NJ. Sleep-disordered breathing after stroke: a randomised controlled trial of continuous positive airway pressure. J Neurol Neurosurg Psychiatry 2006;77(10): 1143-1149

240. Shaw JE, Punjabi NM, Wilding JP, Alberti KG, Zimmet PZ; International Diabetes Federation Taskforce on Epidemiology and Prevention. Sleep-disordered breathing and type 2 diabetes: a report from the International Diabetes Federation Taskforce on Epidemiology and Prevention. Diabetes Res Clin Pract 2008;81(1):2-12

241. Keckeis M, Lattova Z, Maurovich-Horvat E, et al. Impaired glucose tolerance in sleep disorders. PLoS ONE 2010;5(3): e9444

242. Punjabi NM, Shahar E, Redline S, Gottlieb DJ, Givelber R, Resnick HE; Sleep Heart Health Study Investigators. Sleep-disordered breathing, glucose intolerance, and insulin resistance: the Sleep Heart Health Study. Am J Epidemiol 2004;160(6):521-530

243. Punjabi NM, Beamer BA. Alterations in Glucose Disposal in Sleep-disordered Breathing. Am J Respir Crit Care Med 2009;179(3):235-240

244. Aronsohn RS, Whitmore H, Van Cauter E, Tasali E. Impact of untreated obstructive sleep apnea on glucose control in type 2 diabetes. Am J Respir Crit Care Med 2010;181(5):507-513

245. Otake K, Sasanabe R, Hasegawa R, et al. Glucose intolerance in Japanese patients with obstructive sleep apnea. Intern Med 2009;48(21):1863-1868

246. Mahmood K, Akhter N, Eldeirawi K, et al. Prevalence of type 2 diabetes in patients with obstructive sleep apnea in a multi-ethnic sample. J Clin Sleep Med 2009;5(3):215-221

247. Meslier N, Gagnadoux F, Giraud P, et al. Impaired glucoseinsulin metabolism in males with obstructive sleep apnoea syndrome. Eur Respir J 2003;22(1):156-160 
248. Levinson PD, McGarvey ST, Carlisle CC, Eveloff SE, Herbert PN, Millman RP. Adiposity and cardiovascular risk factors in men with obstructive sleep apnea. Chest 1993; 103(5):1336-1342

249. Grunstein RR, Stenlöf K, Hedner J, Sjöström L. Impact of obstructive sleep apnea and sleepiness on metabolic and cardiovascular risk factors in the Swedish Obese Subjects (SOS) Study. Int J Obes Relat Metab Disord 1995; 19(6):410-418

250. Reichmuth KJ, Austin D, Skatrud JB, Young T. Association of sleep apnea and type II diabetes: a population-based study. Am J Respir Crit Care Med 2005;172(12):1590-1595

251. Polotsky VY, Li J, Punjabi NM, et al. Intermittent hypoxia increases insulin resistance in genetically obese mice. J Physiol 2003;552(Pt 1):253-264

252. Tasali E, Leproult R, Ehrmann DA, Van Cauter E. Slowwave sleep and the risk of type 2 diabetes in humans. Proc Natl Acad Sci U S A 2008;105(3):1044-1049

253. Spiegel K, Knutson K, Leproult R, Tasali E, Van Cauter E. Sleep loss: a novel risk factor for insulin resistance and Type 2 diabetes. J Appl Physiol 2005;99(5):2008-2019

254. Hatipoğlu U, Rubinstein I. Inflammation and obstructive sleep apnea syndrome pathogenesis: a working hypothesis. Respiration 2003;70(6):665-671

255. West SD, Nicoll DJ, Wallace TM, Matthews DR, Stradling JR. Effect of CPAP on insulin resistance and HbA1c in men with obstructive sleep apnoea and type 2 diabetes. Thorax 2007;62(11):969-974

256. Babu AR, Herdegen J, Fogelfeld L, Shott S, Mazzone T. Type 2 diabetes, glycemic control, and continuous positive airway pressure in obstructive sleep apnea. Arch Intern Med 2005;165(4):447-452

257. Pallayova M, Donic V, Tomori Z. Beneficial effects of severe sleep apnea therapy on nocturnal glucose control in persons with type 2 diabetes mellitus. Diabetes Res Clin Pract 2008;81(1):e8-e11

258. Yee B, Liu P, Phillips C, Grunstein R. Neuroendocrine changes in sleep apnea. Curr Opin Pulm Med 2004;10(6): 475-481

259. Luboshitzky R, Aviv A, Hefetz A, et al. Decreased pituitary-gonadal secretion in men with obstructive sleep apnea. J Clin Endocrinol Metab 2002;87(7):3394-3398

260. Gambineri A, Pelusi C, Pasquali R. Testosterone levels in obese male patients with obstructive sleep apnea syndrome: relation to oxygen desaturation, body weight, fat distribution and the metabolic parameters. J Endocrinol Invest 2003;26(6):493-498

261. Netzer NC, Eliasson AH, Strohl KP. Women with sleep apnea have lower levels of sex hormones. Sleep Breath 2003;7(1):25-29

262. Lanfranco F, Gianotti L, Pivetti S, et al. Obese patients with obstructive sleep apnoea syndrome show a peculiar alteration of the corticotroph but not of the thyrotroph and lactotroph function. Clin Endocrinol (Oxf) 2004;60(1): 41-48

263. Punjabi NM, Polotsky VY. Disorders of glucose metabolism in sleep apnea. J Appl Physiol 2005;99(5):1998-2007

264. Peker Y, Carlson J, Hedner J. Increased incidence of coronary artery disease in sleep apnoea: a long-term followup. Eur Respir J 2006;28(3):596-602

265. Franklin KA, Nilsson JB, Sahlin C, Näslund U. Sleep apnoea and nocturnal angina. Lancet 1995;345(8957):1085-1087
266. Hung J, Whitford EG, Parsons RW, Hillman DR. Association of sleep apnoea with myocardial infarction in men. Lancet 1990;336(8710):261-264

267. Schäfer H, Koehler U, Ewig S, Hasper E, Tasci S, Lüderitz B. Obstructive sleep apnea as a risk marker in coronary artery disease. Cardiology 1999;92(2):79-84

268. Mooe T, Rabben T, Wiklund U, Franklin KA, Eriksson P. Sleep-disordered breathing in men with coronary artery disease. Chest 1996;109(3):659-663

269. Aboyans V, Cassat C, Lacroix P, et al. Is the morning peak of acute myocardial infarction's onset due to sleep-related breathing disorders? A prospective study. Cardiology 2000; 94(3):188-192

270. Sorajja D, Gami AS, Somers VK, Behrenbeck TR, GarciaTouchard A, Lopez-Jimenez F. Independent association between obstructive sleep apnea and subclinical coronary artery disease. Chest 2008;133(4):927-933

271. Lee CH, Khoo SM, Tai BC, et al. Obstructive sleep apnea in patients admitted for acute myocardial infarction. Prevalence, predictors, and effect on microvascular perfusion. Chest 2009;135(6):1488-1495

272. Peker Y, Hedner J, Kraiczi H, Löth S. Respiratory disturbance index: an independent predictor of mortality in coronary artery disease. Am J Respir Crit Care Med 2000;162(1):81-86

273. Yumino D, Tsurumi Y, Takagi A, Suzuki K, Kasanuki H. Impact of obstructive sleep apnea on clinical and angiographic outcomes following percutaneous coronary intervention in patients with acute coronary syndrome. Am J Cardiol 2007;99(1):26-30

274. Steiner S, Schueller PO, Hennersdorf MG, Behrendt D, Strauer BE. Impact of obstructive sleep apnea on the occurrence of restenosis after elective percutaneous coronary intervention in ischemic heart disease. Respir Res 2008;9:50

275. Nakashima H, Katayama T, Takagi C, et al. Obstructive sleep apnoea inhibits the recovery of left ventricular function in patients with acute myocardial infarction. Eur Heart J 2006;27(19):2317-2322

276. Turmel J, Sériès F, Boulet LP, et al. Relationship between atherosclerosis and the sleep apnea syndrome: an intravascular ultrasound study. Int J Cardiol 2009;132(2): 203-209

277. Gami AS, Rader S, Svatikova A, et al. Familial premature coronary artery disease mortality and obstructive sleep apnea. Chest 2007;131(1):118-121

278. Belaidi E, Joyeux-Faure M, Ribuot C, Launois SH, Levy P, Godin-Ribuot D. Major role for hypoxia inducible factor-1 and the endothelin system in promoting myocardial infarction and hypertension in an animal model of obstructive sleep apnea. J Am Coll Cardiol 2009;53(15): 1309-1317

279. Kuniyoshi FH, Garcia-Touchard A, Gami AS, et al. Daynight variation of acute myocardial infarction in obstructive sleep apnea. J Am Coll Cardiol 2008;52(5):343-346

280. Cassar A, Morgenthaler TI, Lennon RJ, Rihal CS, Lerman A. Treatment of obstructive sleep apnea is associated with decreased cardiac death after percutaneous coronary intervention. J Am Coll Cardiol 2007;50(14):1310-1314

281. Milleron O, Pillière R, Foucher A, et al. Benefits of obstructive sleep apnoea treatment in coronary artery disease: a long-term follow-up study. Eur Heart J 2004; 25(9):728-734 
282. Doherty LS, Kiely JL, Swan V, McNicholas WT. Long-term effects of nasal continuous positive airway pressure therapy on cardiovascular outcomes in sleep apnea syndrome. Chest 2005;127(6):2076-2084

283. Peled N, Abinader EG, Pillar G, Sharif D, Lavie P. Nocturnal ischemic events in patients with obstructive sleep apnea syndrome and ischemic heart disease: effects of continuous positive air pressure treatment. J Am Coll Cardiol 1999;34(6):1744-1749

284. Harbison J, O'Reilly P, McNicholas WT. Cardiac rhythm disturbances in the obstructive sleep apnea syndrome: effects of nasal continuous positive airway pressure therapy. Chest 2000;118(3):591-595

285. Gami AS, Somers VK. Implications of obstructive sleep apnea for atrial fibrillation and sudden cardiac death. J Cardiovasc Electrophysiol 2008;19(9):997-1003

286. Roche F, Gaspoz JM, Court-Fortune I, et al. Alteration of QT rate dependence reflects cardiac autonomic imbalance in patients with obstructive sleep apnea syndrome. Pacing Clin Electrophysiol 2003;26(7 Pt 1):1446-1453

287. Szymanowska K, Piatkowska A, Nowicka A, Cofta S, Wierzchowiecki M. Heart rate turbulence in patients with obstructive sleep apnea syndrome. Cardiol J 2008;15(5): 441-445

288. Gillis AM, Stoohs R, Guilleminault C. Changes in the QT interval during obstructive sleep apnea. Sleep 1991;14(4): 346-350

289. Ito R, Hamada H, Yokoyama A, et al. Successful treatment of obstructive sleep apnea syndrome improves autonomic nervous system dysfunction. Clin Exp Hypertens 2005; 27(2-3):259-267

290. Nakamura T, Chin K, Hosokawa R, et al. Corrected QT dispersion and cardiac sympathetic function in patients with obstructive sleep apnea-hypopnea syndrome. Chest 2004; 125(6):2107-2114

291. Roche F, Barthélémy JC, Garet M, Duverney D, Pichot V, Sforza E. Continuous positive airway pressure treatment improves the QT rate dependence adaptation of obstructive sleep apnea patients. Pacing Clin Electrophysiol 2005;28(8): 819-825

292. Aytemir K, Deniz A, Yavuz B, et al. Increased myocardial vulnerability and autonomic nervous system imbalance in obstructive sleep apnea syndrome. Respir Med 2007;101(6): $1277-1282$

293. Guilleminault C, Connolly SJ, Winkle RA. Cardiac arrhythmia and conduction disturbances during sleep in 400 patients with sleep apnea syndrome. Am J Cardiol 1983; 52(5):490-494

294. Hoffstein V, Mateika S. Cardiac arrhythmias, snoring, and sleep apnea. Chest 1994;106(2):466-471

295. Mehra R, Benjamin EJ, Shahar E, et al; Sleep Heart Health Study. Association of nocturnal arrhythmias with sleepdisordered breathing: The Sleep Heart Health Study. Am J Respir Crit Care Med 2006;173(8):910-916

296. Fuster V, Rydén LE, Cannom DS, et al; American College of Cardiology/American Heart Association Task Force on Practice Guidelines; European Society of Cardiology Committee for Practice Guidelines; European Heart
Rhythm Association; Heart Rhythm Society. ACC/AHA/ ESC 2006 Guidelines for the Management of Patients with Atrial Fibrillation: a report of the American College of Cardiology/American Heart Association Task Force on Practice Guidelines and the European Society of Cardiology Committee for Practice Guidelines (Writing Committee to Revise the 2001 Guidelines for the Management of Patients With Atrial Fibrillation): developed in collaboration with the European Heart Rhythm Association and the Heart Rhythm Society. Circulation 2006;114(7):e257-e354

297. Chen PS, Douglas P. Douglas P. Zipes Lecture. Neural mechanisms of atrial fibrillation. Heart Rhythm 2006; 3(11):1373-1377

298. Asirvatham SJ, Kapa S. Sleep apnea and atrial fibrillation: the autonomic link. J Am Coll Cardiol 2009;54(22):2084-2086

299. Kanagala R, Murali NS, Friedman PA, et al. Obstructive sleep apnea and the recurrence of atrial fibrillation. Circulation 2003;107(20):2589-2594

300. Abe H, Takahashi M, Yaegashi $H$, et al. Efficacy of continuous positive airway pressure on arrhythmias in obstructive sleep apnea patients. Heart Vessels 2010;25(1): 63-69

301. Zwillich C, Devlin T, White D, Douglas N, Weil J, Martin R. Bradycardia during sleep apnea. Characteristics and mechanism. J Clin Invest 1982;69(6):1286-1292

302. Ji KH, Kim DH, Yun CH. Severe obstructive sleep apnea syndrome with symptomatic daytime bradyarrhythmia. J Clin Sleep Med 2009;5(3):246-247

303. Grimm W, Koehler U, Fus E, et al. Outcome of patients with sleep apnea-associated severe bradyarrhythmias after continuous positive airway pressure therapy. Am J Cardiol 2000;86(6):688-692, A9

304. Javaheri S, Parker TJ, Liming JD, et al. Sleep apnea in 81 ambulatory male patients with stable heart failure. Types and their prevalences, consequences, and presentations. Circulation 1998;97(21):2154-2159

305. Sin DD, Fitzgerald F, Parker JD, Newton G, Floras JS, Bradley TD. Risk factors for central and obstructive sleep apnea in 450 men and women with congestive heart failure. Am J Respir Crit Care Med 1999;160(4):1101-1106

306. Wang H, Parker JD, Newton GE, et al. Influence of obstructive sleep apnea on mortality in patients with heart failure. J Am Coll Cardiol 2007;49(15):1625-1631

307. Hedner J, Ejnell H, Caidahl K. Left ventricular hypertrophy independent of hypertension in patients with obstructive sleep apnoea. J Hypertens 1990;8(10):941-946

308. Laaban JP, Pascal-Sebaoun S, Bloch E, Orvoën-Frija E, Oppert JM, Huchon G. Left ventricular systolic dysfunction in patients with obstructive sleep apnea syndrome. Chest 2002;122(4):1133-1138

309. Tkacova R, Rankin F, Fitzgerald FS, Floras JS, Bradley TD. Effects of continuous positive airway pressure on obstructive sleep apnea and left ventricular afterload in patients with heart failure. Circulation 1998;98(21):2269-2275

310. Chen L, Shi Q, Scharf SM. Hemodynamic effects of periodic obstructive apneas in sedated pigs with congestive heart failure. J Appl Physiol 2000;88(3):1051-1060 